\title{
Novel Au-Based Solder Alloys: A Potential Answer for Electrical Packaging Problem
}

\author{
Jiachen Xu $\mathbb{D}^{1},{ }^{1}$ Mingfang $W u\left(\mathbb{D},{ }^{1}\right.$ Juan Pu, ${ }^{1}$ and Songbai Xue $\mathbb{D}^{2}$ \\ ${ }^{1}$ Jiangsu Provincial Key Laboratory of Advanced Welding Technology, Jiangsu University of Science and Technology, \\ Zhenjiang 212003, China \\ ${ }^{2}$ College of Materials Science and Technology, Nanjing University of Aeronautics and Astronautics, Nanjing 210016, China \\ Correspondence should be addressed to Mingfang Wu; wu_mingfang@163.com
}

Received 9 March 2020; Revised 2 May 2020; Accepted 5 May 2020; Published 26 May 2020

Academic Editor: Lingxue Kong

Copyright ( $\odot 2020$ Jiachen Xu et al. This is an open access article distributed under the Creative Commons Attribution License, which permits unrestricted use, distribution, and reproduction in any medium, provided the original work is properly cited.

With the development of electronical technology and the construction of the fifth-generation cellular networks, electronic devices with higher integrated level and power are widely applied. Hence, greater demands are being placed on electronic packaging materials. High- $\mathrm{Pb}$ solder alloys were widely used for low- and medium-temperature soldering for the past decades but have been prohibited due to toxicity. Au-based solder alloys with proper melting and mechanical properties show great potential to replace high- $\mathrm{Pb}$ solder alloys and are being emphasized recently. But in comparison with $\mathrm{Pb}$-containing solder alloys, the investigation on novel $\mathrm{Au}$-based solder alloys is quite insufficient, and their performance and reliability are still unclear. In this paper, the recent research studies on Au-based solder alloys with low temperature and medium temperature were reviewed and their microstructure, mechanical performance, and reliability were introduced and analyzed. Moreover, the novel processing technologies of Au-based solder alloys were discussed and compared.

\section{Introduction}

In the past decades, electronical industry is becoming more and more important for every country due to its significant effect on the development of economy and national security, and many efforts have been made for design and manufacture novel electrical devices [1-3]. Sn-based solder alloys with excellent properties are widely used in electronic packaging, and a few novel Sn-based solder alloys that are applied in the packaging of integrated circuits (IC) have been designed to meet the rising requirement of electrical devices, thanks to the researchers [4-6]. Recently, owing to the development of electronics industry, the high-density packaging technologies for integrated circuits (IC), such as BGA, CSP, IGBT, and WLP, have been applied gradually, promoting the upgrading and miniaturizing process of electrical products $[7,8]$. But miniaturization of ICs with higher power also results in increasingly higher service temperature of more than $300^{\circ} \mathrm{C}$, which puts much emphasis on the electrical devices as well as their packaging materials [9].
Pb-based solder alloys with excellent wettability and suitable melting temperature are widely used in electronic packaging [10-12]. Nevertheless, under the drive of environmentally friendly manufacturing, much requirement has been attached to lead-free solder alloys, among which $\mathrm{Au}$ based solder alloy is seen as an excellent filler metal to replace the $\mathrm{Pb}$-based solder alloy used in high-temperature conditions [13, 14]. Au-Sn [15], Au-Si [16], Au-Ge [17], Au$\mathrm{Sb}$ [18], and other Au-based low-temperature solders with a melting temperature lower than $400^{\circ} \mathrm{C}$ have become the ideal substitute for solder alloys containing high content of lead due to their good wettability, excellent brazing performance, high joint strength, good thermal fatigue resistance, high thermal conductivity, and small dissolution for gold-plated pads $[19,20]$. In recent years, to meet the temperature requirement of high integrated electronic devices, Aubased medium-temperature solder alloys with the melting temperature of $400-600^{\circ} \mathrm{C}$ have received more and more attention, the majority of which are $\mathrm{Au}-\mathrm{Ag}, \mathrm{Au}-\mathrm{In}$, and $\mathrm{Au}-$ Ga solder alloys $[13,21]$. But in comparison with Au-based 
low-temperature solder alloys, the research studies on Aubased medium-temperature solder alloys are still inadequate, which limits their application [22].

Gold-based medium- and low-temperature solders have excellent performance and high reliability, but due to the presence of brittle phases, they have poor processing properties and cannot be manufactured by conventional methods [23]. At present, although many processing methods, such as melt-casting and toughening process, laminated cold rolling process, electroplating deposition process, mechanical alloying process, and rapid solidification process, have been developed and the processing of the foil with the thickness of $0.1 \mathrm{~mm}$ or less has been basically realized, the process is still needed to be improved. Therefore, the development of new processing technologies will be one of the future research directions of gold-based mediumand low-temperature solders. At the same time, in order to reduce the cost of gold-based medium- and low-temperature solder alloys and meet the application requirements of goldbased solders, it is of great significance to develop a new gold-based alloy system [20, 24, 25]. This paper mainly introduced the microstructure and performances of goldbased medium- and low-temperature solders and analyzed the advantages and shortcomings of different preparation processes. Finally, the development direction of gold-based medium- and low-temperature solders was discussed and prospected.

\section{Au-Based Low-Temperature Solder Alloys}

The gold-based low-temperature solder mainly refers to a gold-based solder with a melting temperature less than $400^{\circ} \mathrm{C}$, such as $\mathrm{Au}-\mathrm{Sn}, \mathrm{Au}-\mathrm{Si}, \mathrm{Au}-\mathrm{Ge}$, and $\mathrm{Au}-\mathrm{Sb}$ [15-18]. Gold-based low-temperature solders have excellent wettability, thermomechanical properties, and high corrosion resistance, which are the main soldering materials for hermetic packaging.

\subsection{Au-Sn Solder}

2.1.1. Matrix Microstructure. In comparison with other Aubased solder alloys, Au-Sn solder possesses higher electrical conductivity, more excellent creep resistance, and solderability [27]. Hence, Au-Sn solder alloys, the majority of which is Au-20Sn eutectic solder, are seen as the ideal filler metal for optoelectronic packages. With the advancement of manufacturing technology of electrical devices, Au-Sn solder shows great potential for the packaging of future precise instruments and has been obtaining more attention recently. The microstructure of Au-20Sn solder consists of two brittle intermetallic compounds (IMC): $\mathrm{Au}_{5} \mathrm{Sn}(\xi)$ and $\mathrm{AuSn}(\delta)$, which disperse evenly and form the eutectic structure [28]. The well-distributed morphology of $\mathrm{Au}_{5} \mathrm{Sn}(\xi)$ and $\mathrm{AuSn}(\delta)$ gives a high strength of as-soldered $\mathrm{Au}-\mathrm{Sn}$ joint, which would be affected by the service temperature, however. As illustrated in Figure 1, the majority of microstructure in the soldered joint was identified to be a fine eutectic structure and some $\xi$ particles dispersed in the matrix [26]. After longterm thermal aging at $150^{\circ} \mathrm{C}$, the growing behavior of $\xi$ particles could be observed, but the eutectic microstructure was hardly changed. However, if the aging temperature rose to be $200^{\circ} \mathrm{C}$, the fine eutectic microstructure would be destroyed and only thick $\xi$ and $\delta$ phases could be obtained. Therefore, the service temperature of $\mathrm{Au}$-Sn solder should be concerned, especially for the packaging of future high-power electrical devices.

2.1.2. Interfacial Microstructure. The IMC layer that forms between solder matrix and substrate during soldering process is the foundation of reliable bonding, whose morphology and property play an important role in the solder joint [7]. After soldering process, a $\xi$ - $(\mathrm{Au}, \mathrm{Cu})_{5} \mathrm{Sn}$ thick IMC layer with irregular columnar morphology and a very thin $\mathrm{Au}-\mathrm{Cu}$ IMC layer formed at the interface of the $\mathrm{Au}-\mathrm{Sn} / \mathrm{Cu}$ solder joint $[29,30]$. But this Au-Cu IMC layer was claimed to be sensitive to the service temperature. The atomic migration of $\mathrm{Cu}$ from $\mathrm{Cu}$ substrate to solder matrix was significantly accelerated at high temperature, and hence, $\mathrm{Cu}$ content at the interface was increased, giving a new interfacial layer [31]. As illustrated in Figure 2, after being aged, at $200^{\circ} \mathrm{C}$, the thickness of the $\mathrm{Cu}-\mathrm{Au}$ IMC layer was greatly increased with the formation of a new $\mathrm{Cu}_{3} \mathrm{Au}$ layer, and hence, a bilayer of $\mathrm{CuAu} / \mathrm{Cu}_{3} \mathrm{Au}$ between $\xi$ - $(\mathrm{Au}, \mathrm{Cu})_{5} \mathrm{Sn}$ and $\mathrm{Cu}$ substrate formed, which coarsened with the progress of thermal aging [32]. The same phenomenon could be observed in the Au-Sn/Ni solder joint [33]. In the as-soldered $\mathrm{Au}-\mathrm{Sn} / \mathrm{Ni}$ solder joint, a thick $\delta$ layer and a thin $(\mathrm{Au}, \mathrm{Ni})_{3} \mathrm{Sn}_{2}$ layer formed at the interface [34]. During the aging test, the $\mathrm{Ni}$ atom migrated from the substrate and reacted with the $\delta$ phase, forming the (Au, Ni)Sn IMC layer. But compared with $\mathrm{Cu}$ substrate, the migration speed of $\mathrm{Ni}$ from $\mathrm{Ni}$ substrate to interface was much lower, and hence, the growth of $(\mathrm{Au}, \mathrm{Ni})_{3} \mathrm{Sn}_{2}$ and $(\mathrm{Au}, \mathrm{Ni}) \mathrm{Sn}$ IMC layer was relatively slower [35]. Moreover, the oxygen content of the Au-Sn solder matrix was also found to be an adverse factor for the morphology and strength of interfacial layer. Wang et al. [36] found that once the oxygen content exceeded $42 \mathrm{ppm}$, the oxygen would be entrapped in the $\mathrm{Au}-\mathrm{Sn} / \mathrm{Cu}$ solder joint during the soldering process and formed a number of voids, even a few cracks, which would deteriorate the property of solder joint. Therefore, it is of great significance to focus on the storage condition of Au-Sn solder alloys.

2.1.3. Mechanical Property. Due to higher brittleness of IMC phase than solder matrix, the brittle fracture of Au-Sn solder joint is always a problem for electrical packaging, especially for those applied in high-temperature conditions [37]. The formation of IMC layer is the foundation of reliable bonding between solder matrix and substrate, but the morphology of IMC layer significantly affects the property of solder joint [38]. During the service condition, the coefficient of thermal expansion (CTE) mismatch of solder matrix and substrate put much thermal stress at the interface, where the existence of thick brittle IMC layer provides the crack source and increases the fracture risk of solder joint [39]. Recently, some researchers tried to suppress the precipitation of $\mathrm{Au}_{5} \mathrm{Sn}$ and precipitate relatively ductile phases by doping Ag or $\mathrm{Cu}$. Ag 

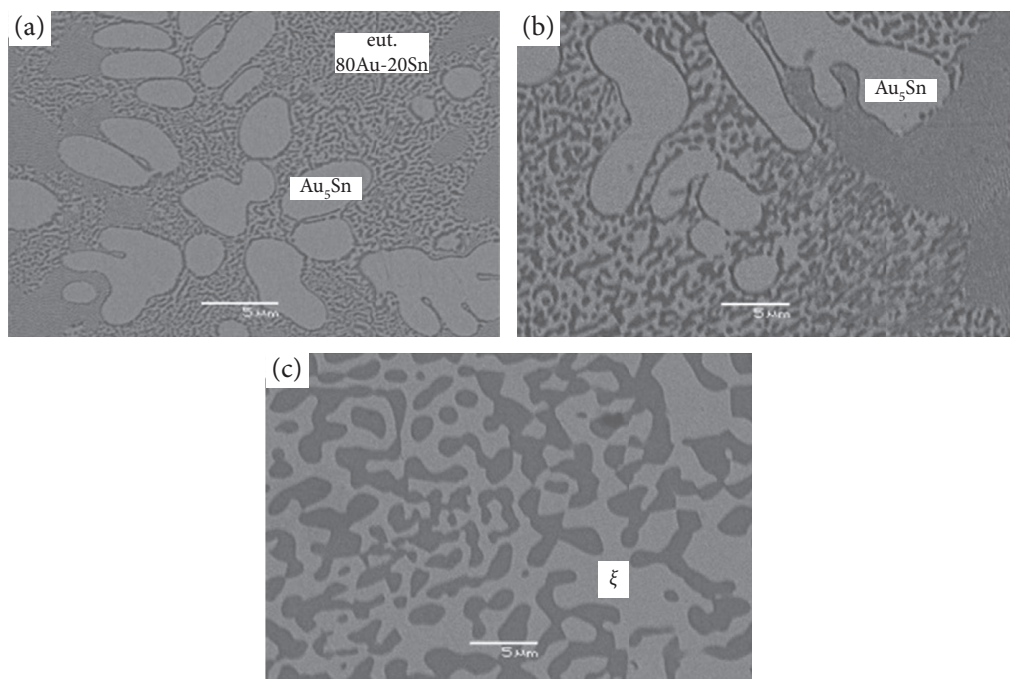

FIGURE 1: SEM-BSE micrographs of eutectic Au-Sn alloy depicting the phase transformations during thermal aging. (a) As-produced, (b) $150^{\circ} \mathrm{C}$, 1 week, and (c) $200^{\circ} \mathrm{C}, 1$ week [26].

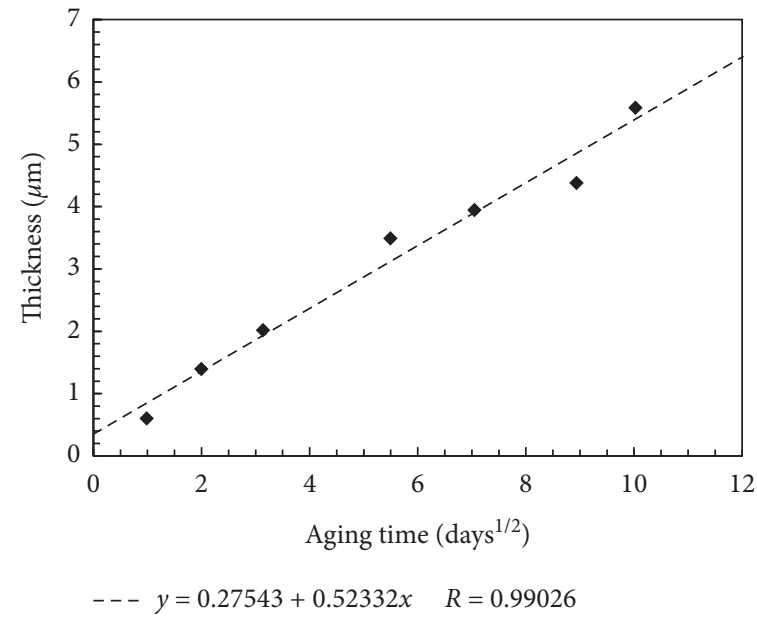

(a)

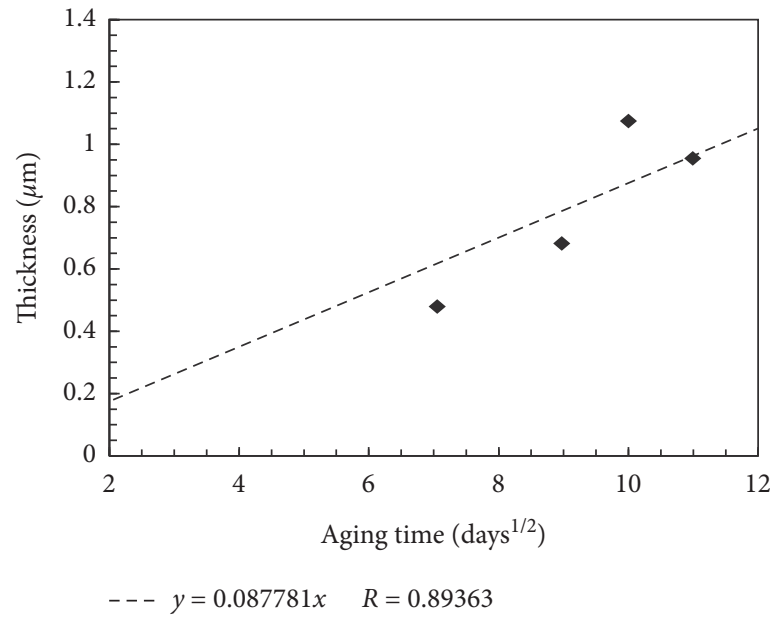

(b)

Figure 2: Thickness of (a) the $\mathrm{Cu}-\mathrm{Au}$ layer and (b) the $\mathrm{Cu}_{3} \mathrm{Au}$ layer in solder bumps with the square root of aging time at 200 ${ }^{\circ} \mathrm{C}$ [32].

and $\mathrm{Cu}$ elements could perform as the solid solute in $\mathrm{Au}_{5} \mathrm{Sn}$, blocking the atomic migration and increasing glide resistance of grain boundary and hence gave a fine morphology of $\mathrm{Au}_{5} \mathrm{Sn}$ [40]. As a result, a higher reliability of $\mathrm{Au}-\mathrm{Sn}$ solder was obtained. Jung et al. [41] investigated the effect of thermal aging on the fracture behavior of the eutectic Au-Sn/ $\mathrm{Ni}$ solder joint and found that for the soldered joint, the fracture tended to initiate and prolongate in the solder matrix, where only the solder matrix was observed on the fracture surface. But as shown in Figure 3, the fracture location was changed to be the interface of solder matrix and IMC layer after thermal aging, which was attributed to coarsening of the $(\mathrm{Au}, \mathrm{Ni})_{3} \mathrm{Sn}_{4}$ IMC layer. The voids and cracks that formed during thermal aging process hardly affected the shear force and fracture location, which indicated that the excessive growth of IMC layer was the main deteriorating factor for the solder joint. In comparison with
$\mathrm{Cu}$ substrate, the growth behavior of IMC layer in the $\mathrm{Au}$ $\mathrm{Sn} / \mathrm{Ni}$ solder joint was found to be more unobvious during thermal aging, which gave a relatively lower strength decrement. It could be seen from Figure 4 that the shear force of $\mathrm{Au}-\mathrm{Sn} / \mathrm{Ni}$ solder bump was hardly decreased after aged at $150^{\circ} \mathrm{C}$ for $1000 \mathrm{~h}$, which indicated the solder bump had an excellent reliability [33].

2.1.4. Solderability. Eutectic Au-Sn solder with excellent wettability and a melting temperature $\left(T_{\mathrm{m}}\right)$ of $278^{\circ} \mathrm{C}$ can meet the requirements of high-end electronic components, such as military products and aerospace industry. But due to its narrow liquidus range around eutectic chemical composition, the soldering processing window is quite limited. Moreover, the inert barrier metallization, the majority of which is $\mathrm{Ti} / \mathrm{Pt} / \mathrm{Au}$, has been applied to avoid the 

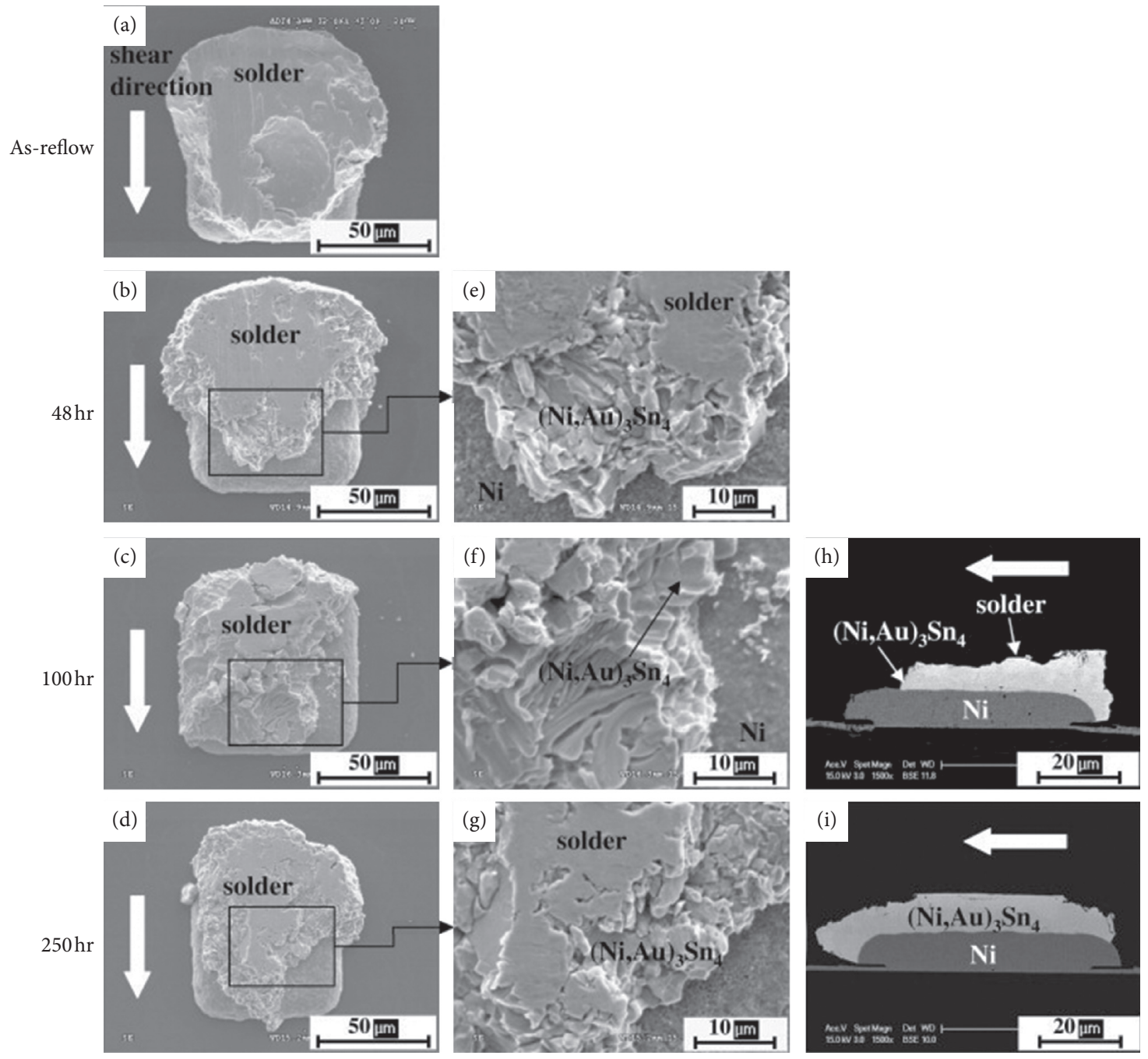

Figure 3: Top views and cross-sectional SEM images of the fracture surfaces of eutectic Au-Sn/Ni joints aged under various conditions [41].

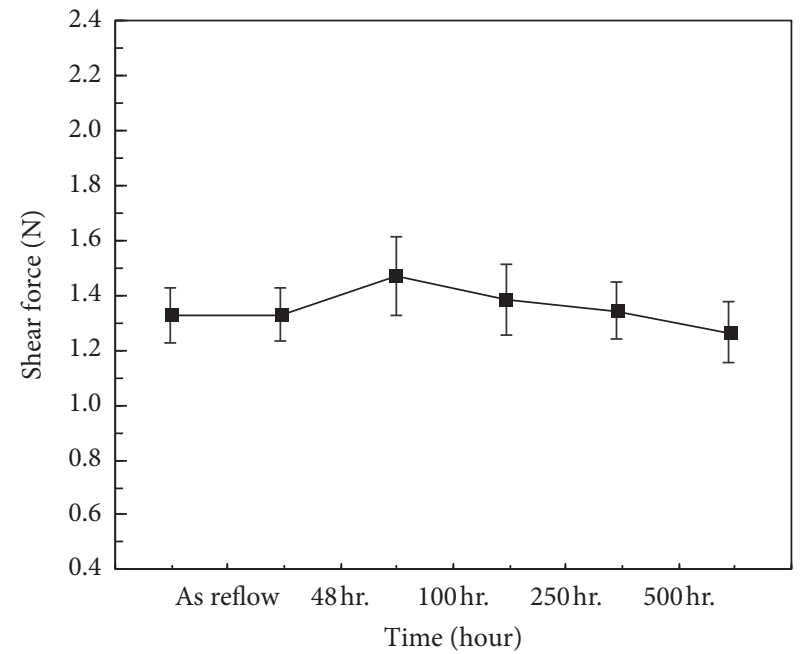

FIgURE 4: Shear force variation of $\mathrm{Au}-\mathrm{Sn} / \mathrm{Ni}$ solder bump with aging time [33]. deterioration of eutectic solder matrix [42]. However, it was found that this barrier metallization layer resulted in the consumption of Sn from solder matrix and the premature freezing of the thin solder layer, giving a decrease in strength of the solder joint. Therefore, a new barrier metallization of $\mathrm{Ti} / \mathrm{W} / \mathrm{W}-\mathrm{NiSn} / \mathrm{NiSn}$ showed excellent application potential for Au-Sn solder alloys at all processing temperatures because the existence of $\mathrm{W}-\mathrm{NiSn}$ and NiSn provided an excellent solution to ensure a perfect adhesion of molten solder matrix and substrate [43]. What is more, it had been found that the reflow process of AuSn solder alloy should be focused [29]. Liu et al. [44] studied the effect of reflow parameter on the wetting reaction between Au-Sn solder and $\mathrm{Au}$ foil and found that the best wettability of molten Au-Sn solder was obtained at $390^{\circ} \mathrm{C}$, giving a wetting angle of $25^{\circ}$. The oxidation of the Au-Sn solder matrix was greatly accelerated above $390^{\circ} \mathrm{C}$, which could retard the soldering process. For the $\mathrm{Au}-\mathrm{Sn} / \mathrm{Ni}$ solder joint, a short reflow time gave an insufficient wetting of molten solder, while a long 
reflow time led to the excessive growth of $(\mathrm{Au}, \mathrm{Ni})_{3} \mathrm{Sn}_{2} \mathrm{IMC}$, which would be spalled from the interface and embedded in the solder matrix [45]. Hence, the strength of solder joint was greatly reduced. The oxygen content of AuSn solder matrix was also claimed to affect its solderability. As it could be seen from Figure 5, the increasing oxygen content gave a lower spreading area, whether flux was applied or not [36]. The reason was that the high content of oxygen element was absorbed at the surface of the solder matrix and led to the formation of $\mathrm{SnO}$ and $\mathrm{SnO}_{2}$ oxide films, which hindered the spreading process and the interfacial reaction of molten solder matrix and substrate during the soldering process.

\subsection{Au-Ge Solder}

2.2.1. Microstructure. Au-Ge solder alloys have many advantages, such as low vapor pressure, high stability, corrosion resistance, thermal fatigue resistance, high electrical conductivity, and thermal conductivity, which are widely used in chip soldering and packaging [46]. Figure 6 exhibited the microstructure of eutectic Au-Ge solder alloys [47]. As illustrated in Figure 6(a), the $\mathrm{Au}$ phase (bright phase) and Ge phase (dark phase) distributed alternately in the solder matrix. The Au phase was a soft phase, whereas the Ge phase was a hard phase, and the later one with fine morphology could help enhance the solder matrix by acting as a strengthening phase. But after thermal aging at $300^{\circ} \mathrm{C}$ for $100 \mathrm{~h} \sim 500 \mathrm{~h}$, it could be seen from Figures 6(b)-6(f) that the Ge phase coarsened with time and then the dissolution of Ge into the Au phase was observed. Moreover, the thermal aging also influenced the interfacial microstructure of the $\mathrm{Au}$-Ge solder joint. In the soldered $\mathrm{Au}-\mathrm{Ge}$ joint on $\mathrm{Cu} / \mathrm{Au}$ under bump metallization (UBM), a continuous $(\mathrm{Au}, \mathrm{Cu})$ layer formed at the interface, as shown in Figure 7(a) [47]. But the subsequent thermal aging destroyed this morphology, and the continuous diffusion of $\mathrm{Cu}$ atoms from UBM into solder matrix led to the spalling behavior, as shown in Figure 7(b). In the eutectic Au-Ge/ENIG solder joint, the oxidation of $\mathrm{Cu}$ layer occurred between $\mathrm{Ni}-\mathrm{Ge}$ IMC layer and $\mathrm{Cu}$ substrate during the thermal aging, which decreased the mechanical properties of solder joint [48].

2.2.2. Mechanical Property. As a kind of low-temperature solder alloy, the mechanical property of eutectic Au-Ge solder alloys is excellent. It has been found that the tensile strength of eutectic Au-Ge solder was more than five times higher than $\mathrm{SnPb}$ solder at room temperature and ten times at $120^{\circ} \mathrm{C}$ [49]. The substrate materials could greatly influence the mechanical property of solder joint. As listed in Table 1, the shear strength of $\mathrm{Ni} / \mathrm{Au}-\mathrm{Ge} / \mathrm{Ni}$ solder joint was obviously higher than the others because of the formation of $\mathrm{Cu}$ diffusion layer and high-strength $\mathrm{Ni}_{5} \mathrm{Ge}_{3}$ IMC layer [50]. The eutectic Au-Ge solder has superior high-temperature reliability than $\mathrm{Au}-\mathrm{Si}$ solder, so it is widely used in high-temperature packaging, such as oil and gas exploration and other special industrial fields that require long-term high-temperature operation [51]. But

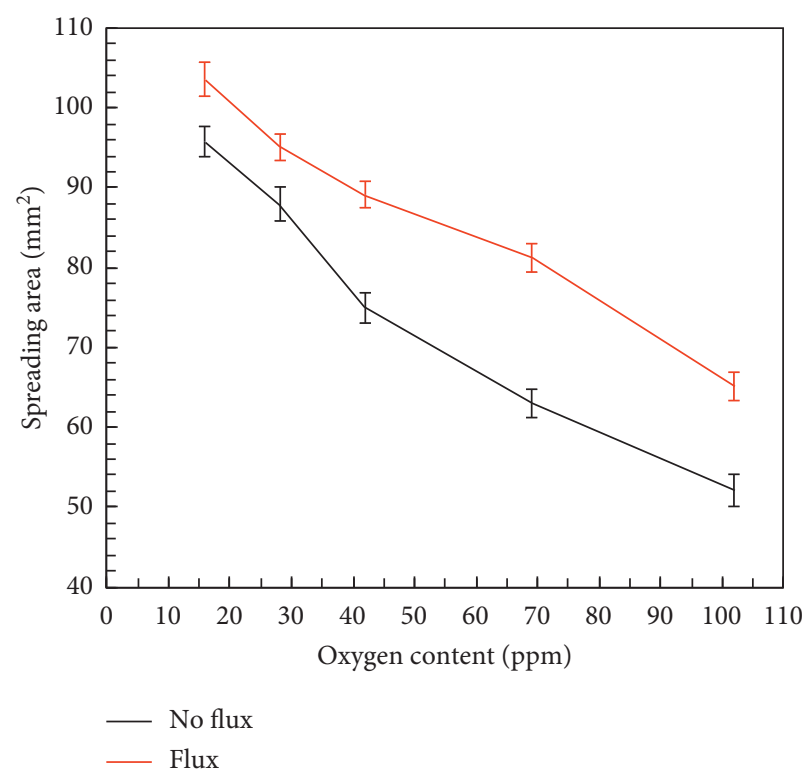

FIgURE 5: Spreading areas of Au-20Sn solders of 16, 28, 42, 69, and 102 atom ppm oxygen, respectively [36].

the decrease in strength of Au-Ge solder joint during thermal aging is always a problem for electronical packaging, and many efforts have been carried out. The strength of Au-Ge/ENIG solder joint would be significantly decreased during thermal aging due to the conductive oxidation of $\mathrm{Cu}$. But as shown in Figure 8, A W diffusion barrier (DB) could effectively block the atomic migration between solder matrix and substrate, which suppressed the diffusion of $\mathrm{Cu}$ atoms and enhanced the reliability of the eutectic Au-Ge/ENIG solder joint [48]. Yang et al. [52] prepared a $200 \mathrm{~nm}$-thick $\mathrm{Ta} / \mathrm{TaN} / \mathrm{Ta}$ diffusion barrier layer on Ni substrate and found that the interfacial reaction between $\mathrm{Au}-\mathrm{Ge}$ solder and $\mathrm{Ni}$ was greatly postponed, which gave a lower growth rate of $\mathrm{Ni}_{5} \mathrm{Ge}_{3}$ IMC layer during thermal aging. Subjected to a long-term thermal aging at $330^{\circ} \mathrm{C}$, the solder joint with $\mathrm{Ta} /$ TaN/Ta DB still gave a shear strength of $56 \mathrm{MPa}$, which was hardly reduced compared with the soldered joint.

2.2.3. Solderability. The wettability of molten $\mathrm{Au}-\mathrm{Ge}$ solder alloys on various substrates is much different. The wetting angle of eutectic $\mathrm{Au}-\mathrm{Ge}$ solder was $14^{\circ}$ for $\mathrm{Cu}$ and $13^{\circ}$ for $\mathrm{Ni}$ substrate, showing an excellent wettability [53]. This could be attributed to the interfacial reaction between eutectic $\mathrm{Au}-\mathrm{Ge}$ solder alloys and the substrates. The dissolution of $\mathrm{Cu}$ and $\mathrm{Ni}$ into the solder matrix formed the interfacial IMC layer and promoted the soldering process, exhibiting a dissolutive wetting characteristic [54]. The wettability of $\mathrm{Au}-\mathrm{Ge}$ solder alloys on $\mathrm{SiC}$ substrate was very unsatisfactory, and the increase in the Ge content was claimed to be helpful to promote the wetting process. But the enhancing effect of Ge addition was limited, the contact angle of Au-Ge solder with 2.8 at. \% of Ge was still as high as $110^{\circ}$ [55]. Therefore, it is necessary to clarify the wettability mechanism of molten Au-Ge solder alloy and find the 

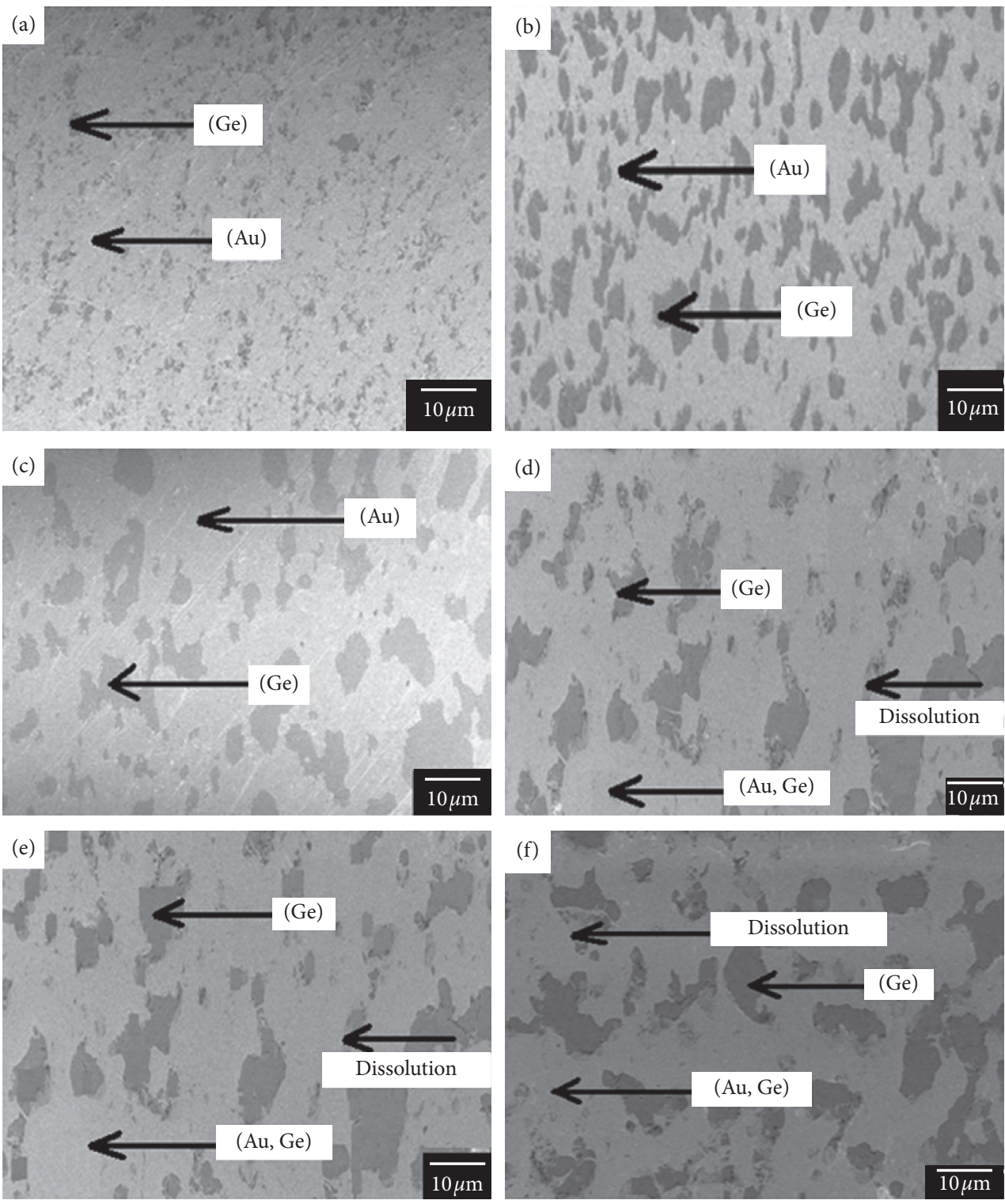

FIGURE 6: SEM secondary electron imaging (SEI) micrographs of Au-Ge eutectic alloy: (a) without thermal aging and after (b) $100 \mathrm{~h}$, (c) $200 \mathrm{~h},(\mathrm{~d}) 300 \mathrm{~h},(\mathrm{e}) 400 \mathrm{~h}$, and (f) $500 \mathrm{~h}$ of thermal aging at $300^{\circ} \mathrm{C}$ [47].
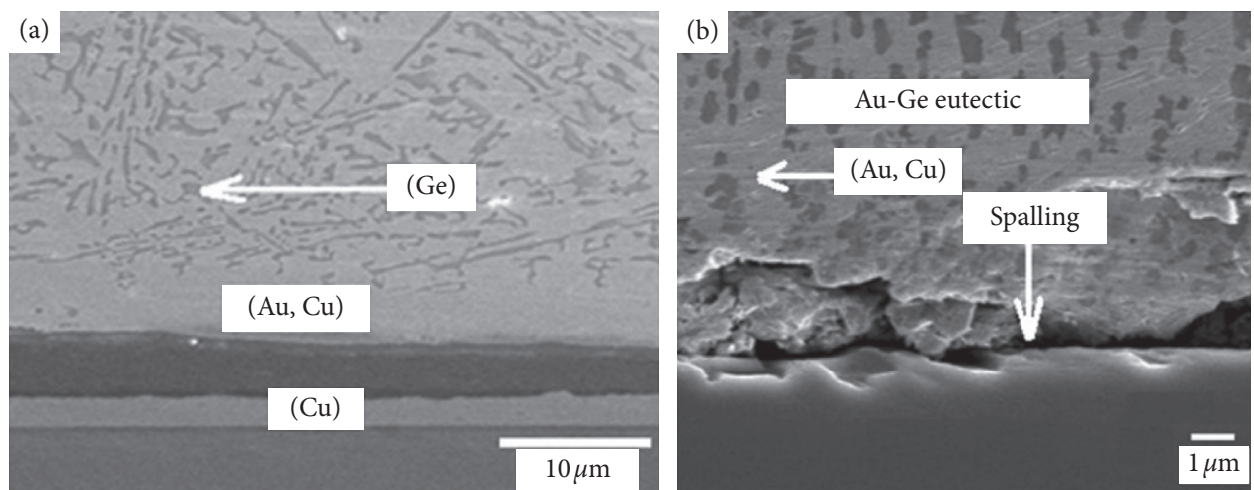

FIGURE 7: SEM-SEI micrographs of the cross section between Au-Ge eutectic solder and Cu/Au UBM: (a) without thermal aging and (b) after thermal aging for $500 \mathrm{~h}$ at $300^{\circ} \mathrm{C}$ [47]. 
TABLE 1: Shear strength of Au-28Ge solder joints on different substrates [50].

\begin{tabular}{lccccc}
\hline Solder & Substrate & Mean value $(\mathrm{MPa})$ & Standard deviation $(\mathrm{MPa})$ & Min value $(\mathrm{MPa})$ & $\mathrm{Max}$ value $(\mathrm{MPa})$ \\
\hline \multirow{4}{*}{$\mathrm{Au}-28 \mathrm{Ge}$} & $\mathrm{Cu}-\mathrm{Ni}$ & 121 & 11 & 109 & 142 \\
& $\mathrm{Cu}-\mathrm{Ti}$ & 68 & 24 & 29 & 48 \\
& $\mathrm{Ni}-\mathrm{Ti}$ & 38 & 8 & 23 & 48 \\
\hline
\end{tabular}

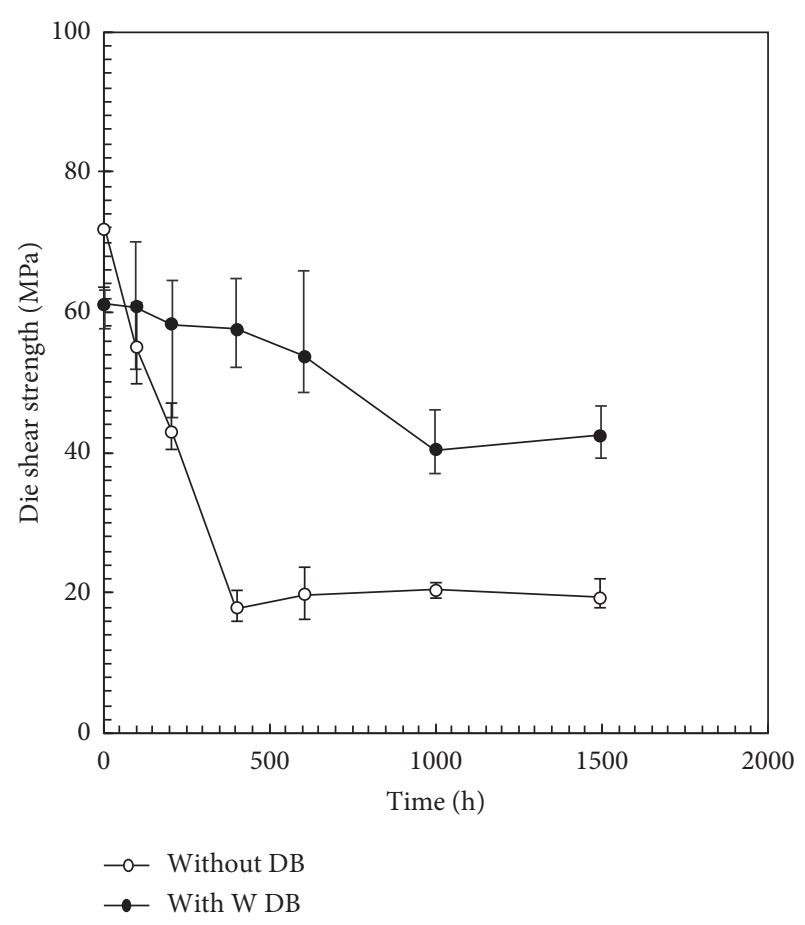

FIGURE 8: Influence of aging time on the die shear strength of AuGe/ENIG solder joint with or without W-DB [48].

relevant enhancing method to meet the requirement of electronic packaging [56].

\subsection{Au-Si Solder}

2.3.1. Microstructure. Au-Si solder alloys have high-temperature oxidation resistance, satisfying thermal conductivity and electrical conductivity, and good electromigration resistance and mechanical properties, which make it quite suitable for electronic device packaging with high power and high integration. It could be seen from the binary phase diagram in Figure 9 that, although $\mathrm{T}_{\mathrm{m}}$ of pure $\mathrm{Au}$ and that of $\mathrm{Si}$ metals are both higher than $1000^{\circ} \mathrm{C}$, eutectic Au-Si solder alloys, consisting of 18 at.\% of $\mathrm{Si}$, possess a melting temperature as low as $363^{\circ} \mathrm{C}$, which meets the requirement of low-temperature soldering [57]. The $T_{\mathrm{m}}$ and density $(\rho)$ of eutectic $\mathrm{Au}-\mathrm{Si}$ solder alloys are similar to that of eutectic Au-Ge, but eutectic Au-Si solder alloys exhibit better property than $\mathrm{Au}-\mathrm{Ge}$ with higher ultimate tensile strength $\left(\sigma_{\mathrm{UTS}}\right)$ and lower CTE from room temperature (RT) to $400^{\circ} \mathrm{C}$, as listed in Table 2 [58]. The solid solubility of $\mathrm{Si}$ in $\mathrm{Au}$ is small, and $\mathrm{Au}$ is substantially insoluble in Si. Therefore, $\mathrm{Au}-\mathrm{Si}$ eutectic alloys are composed of Au-rich $\alpha$ solid

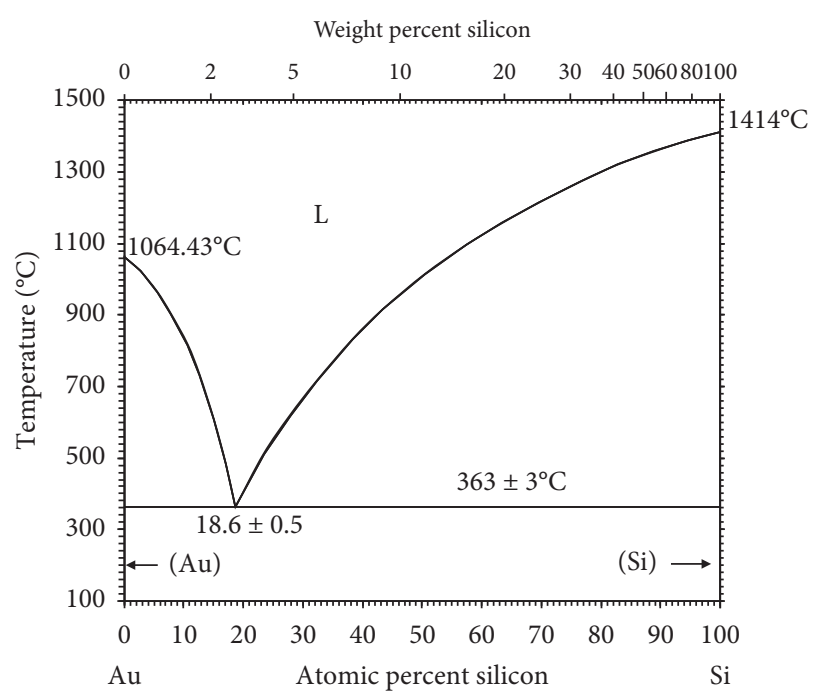

Figure 9: Binary phase diagram of Au-Si system [57].

Table 2: Properties of eutectic Au-Si and Au-Ge solder alloys [58].

\begin{tabular}{lcccc}
\hline Solder & \multicolumn{4}{c}{ Properties } \\
& $\begin{array}{c}\rho \\
\left(\mathrm{kg} \cdot \mathrm{m}^{3}\right)\end{array}$ & $\begin{array}{c}\sigma_{\mathrm{UTS}} \\
(\mathrm{MPa})\end{array}$ & $\begin{array}{c}T_{\mathrm{m}} \\
\left({ }^{\circ} \mathrm{C}\right)\end{array}$ & $\begin{array}{c}\mathrm{CTE}\left(\mathrm{RT}-400^{\circ} \mathrm{C}\right) \\
\left(10^{-6} \cdot \mathrm{K}^{-1}\right)\end{array}$ \\
\hline $\mathrm{Pb}-5 \mathrm{Sn}$ & 10.8 & 36 & 314 & 28.4 \\
$\mathrm{Au}-20 \mathrm{Sn}$ & 14.51 & 338.3 & 280 & 15.9 \\
$\mathrm{Au}-3 \mathrm{Si}$ & 15.7 & 255 & 363 & 12.3 \\
$\mathrm{Au}-12 \mathrm{Ge}$ & 14.67 & 185 & 361 & 13.4 \\
\hline
\end{tabular}

solution and Si phase. The brittle Si phase would deteriorate the mechanical properties of the solder joint, which should be concerned. During thermal aging, the migration of Si particles was greatly accelerated, resulting in the formation of Au-rich zone at the joint center, and the inhomogeneity microstructure was obtained with micro defects induced by thermal stress, as illustrated in Figure 10 [47].

2.3.2. Mechanical Property. The high strength of eutectic Au$\mathrm{Si}$ solder alloys makes it an excellent filler metal for the electronic system. It has been found that the three-dimensional Si-based micro-electrical system could be assembled well by eutectic Au-Si solder alloys, where a bond strength of up to $65 \mathrm{MPa}$ was obtained [59]. But there are also some research studies claiming that the bonding effect of eutectic Au-Si solder on $\mathrm{Si}$ wafers with $\mathrm{Cr}$ or $\mathrm{Ti}$ metallization was not reliable enough, which limited its application $[60,61]$. As listed in Table 3, the shear strength of eutectic Au-Si solder on two different substrates of $\mathrm{Cu} / \mathrm{Au}$ and ENIG were both decreased during a thermal aging of $300^{\circ} \mathrm{C}$, and the subsequent hot shear 

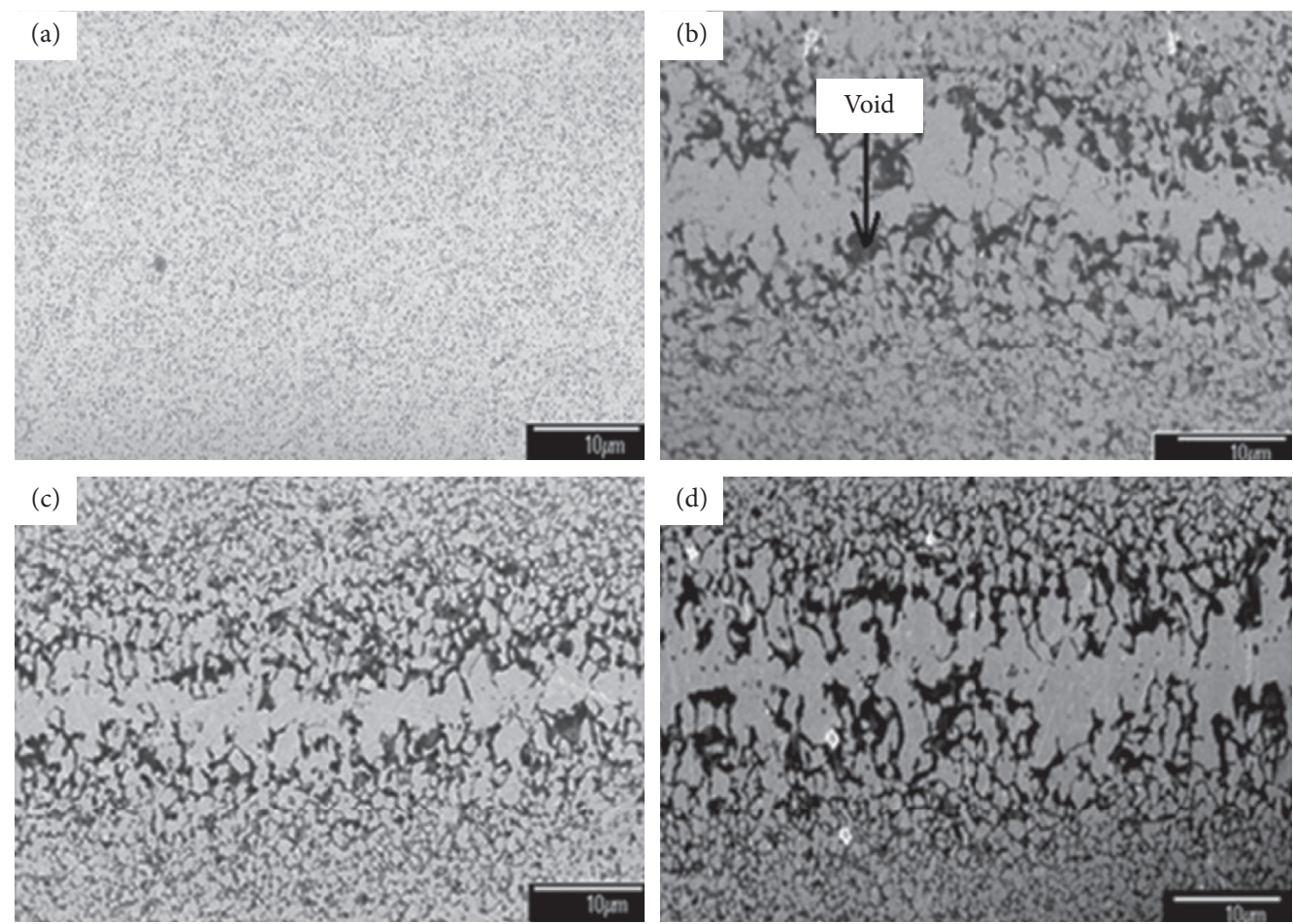

FIGURE 10: SEM images of Au-Si eutectic alloy: (a) without thermal aging and after (b) $100 \mathrm{~h}$, (c) $300 \mathrm{~h}$, and (d) $500 \mathrm{~h}$ of thermal aging at $300^{\circ} \mathrm{C}[47]$.

TABLE 3: Shear strength of $\mathrm{Au}-\mathrm{Si}$ eutectic alloys with $\mathrm{Cu} / \mathrm{Au}$ and ENIG UBM before and after thermal aging at $300^{\circ} \mathrm{C}$ for various durations [47].

\begin{tabular}{lccc}
\hline Solder joint & Aging time $(\mathrm{h})$ & Shear strength at RT $\left(\mathrm{g} \cdot \mathrm{mil}^{-2}\right)$ & ${\text { Shear strength at } 250^{\circ} \mathrm{C}\left(\mathrm{g} \cdot \mathrm{mil}^{-2}\right)}$ \\
\hline & 0 & 6.5 & 5.2 \\
$\mathrm{Au}-\mathrm{Si} / \mathrm{Au} / \mathrm{Cu}$ & 100 & 4.7 & 3.3 \\
& 300 & 2.2 & 1.7 \\
& 500 & 1.8 & 1.3 \\
$\mathrm{Au}-\mathrm{Si} / \mathrm{ENIG}$ & 0 & 6.9 & 5.9 \\
& 100 & 5.8 & 5 \\
& 300 & 5 & 4.6 \\
\hline
\end{tabular}

gave a further decrement [47]. This phenomenon was ascribed to the coarsening behavior of grains in Au-Si solder joint, which indicated that eutectic AuSi might not be a proper choice for high-temperature application.

2.3.3. Solderability. At present, there are two main bonding process types of $\mathrm{Au}-\mathrm{Si}$ eutectic alloys. One is to place $\mathrm{Au}-\mathrm{Si}$ eutectic solder between the silicon chip and the substrate, and then heat and melt to form a eutectic solder joint; the second is to put an Au film on the substrate by vapor deposition or electroplating and then place the silicon chip on the substrate to achieve a eutectic solder joint under pressure with heating, and so on. The solderability of molten Au-Si solder alloy on $\mathrm{SiO}_{2}$ and $\mathrm{SiC}$ substrates was very excellent, and the wetting angle of $0 \sim 30^{\circ}$ could be obtained $[62,63]$. This indicated that Au-Si solder alloys possessed potential for the micro-packaging with $\mathrm{SiO}_{2}$ and $\mathrm{SiC}$ substrates. But the wettability of Au-Si solder on Si substrate was claimed to be quite unsatisfactory, and the wetting angle of up to $165^{\circ}$ could be observed, which rose with the increasing temperature, as shown in Figure 11 [64].

2.4. Au-Sb Solder. Au-Sb eutectic solder has an Sb content of $25 \%$ (mass fraction) and a melting temperature of $360^{\circ} \mathrm{C}$. The $\mathrm{Au}-\mathrm{Sb}$ solder is mainly used for soldering semiconductor devices whose joints require good electrical conductivity and corrosion resistance. However, $\mathrm{Sb}$ is considered to be a potentially toxic element [21] and hence affects the application of the solder alloy.

\section{Au-Based Medium-Temperature Solder Alloys}

In order to meet the higher requirements for the melting temperature and thermal performance of solders due to the miniaturization, intelligence, and high power of electronic products, the research and development of gold-based medium-temperature solders have received increasing 


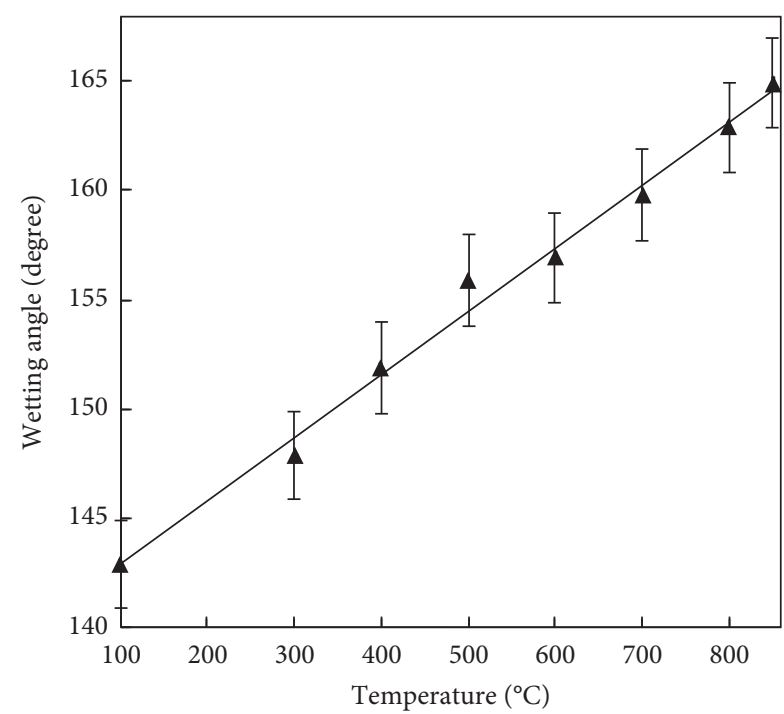

FIGURE 11: Variation of contact angle (measured in the gas phase) as a function of temperature on Si [64].

attention. Solder systems such as $\mathrm{Au}-\mathrm{Ag}, \mathrm{Au}-\mathrm{In}$, and $\mathrm{Au}-\mathrm{Ga}$ have good solderability and great application potential.

3.1. Au-Ag Solder. Au-Ag solder is seen an excellent filler metal to replace high- $\mathrm{Pb}$ solder alloys in the electronic packaging of electrical devices and the interconnection of their casings, the majority of which are $\mathrm{Au}-\mathrm{Ag}-\mathrm{Si}$ and $\mathrm{Au}-$ Ag-Ge solder alloys.

3.1.1. Microstructure. Au-Ag-Si solder is mainly composed of $\mathrm{Au}$ element and contains a small amount of $\mathrm{Ag}$ and $\mathrm{Si}$ elements. The Au-Ag-Si solder is mainly composed of an $\alpha-\mathrm{Au}(\mathrm{Ag})$ phase and $\beta$-Si phase. Because a large number of $\beta$ phases exist in the solder matrix and are network-like distribution, the solder alloy has high brittleness and cannot be processed by traditional cold rolling processing methods [65]. The interfacial microstructure of $\mathrm{Au}-\mathrm{Ag}-\mathrm{Si} / \mathrm{Ni}$ solder joint at different soldering temperatures is shown in Figure 12 [66]. During the soldering process, $\mathrm{Si}$ atoms in the molten $\mathrm{Au}-\mathrm{Ag}$-Si solder matrix migrated into Ni substrate, while the $\mathrm{Ni}$ element dissolved into the solder matrix, forming the $\mathrm{Ni}_{3} \mathrm{Si}$ IMC layer. This IMC layer coarsened with the increasing temperature due to the accelerated atomic migration, giving a hill-like morphology, as illustrated in Figures 12(b) and 12(c). The Au-Ag-Ge solder consists of a primary $\alpha$ phase and a $\beta$ phase containing a large amount of Ge element [21, 67]. Since the $\beta$ phase is a brittle phase, it is difficult for the alloy to be rolled into a ribbon or pulled into a wire by general methods [68]. The microstructure of Au$\mathrm{Ag}-\mathrm{Ge} / \mathrm{Ni}$ solder joint was found to be quite similar to that of $\mathrm{Au}-\mathrm{Ag}-\mathrm{Si} / \mathrm{Ni}$ solder joint. $\mathrm{A} \mathrm{Ge}_{3} \mathrm{Ni}_{5} \mathrm{IMC}$ layer formed at the interface, and its excessive growth would be obtained if the soldering temperature was improved, as showed in Figure 13 [69]. The thick $\mathrm{Ge}_{3} \mathrm{Ni}_{5}$ IMC layer with high brittleness deteriorated the mechanical property of solder joint, and hence the soldering parameters of Au-Ag-Ge solder alloys should be greatly concerned.

3.1.2. Solderability. Table 4 lists melting properties of various $\mathrm{Au}-\mathrm{Ag}$ solder alloys [70]. The Au-Ag-Si solder has good wettability on nickel plates, nickel-plated copper plates, and copper plates but could not wet silver. After the solder alloy was melted on the Ni plate, a wetting ring phenomenon occurred, which was mainly composed of Au elements. The interfacial microstructure analysis showed that $\mathrm{Ni}_{3} \mathrm{Si}$ intermetallic compound formed at the interface between the solder and the $\mathrm{Ni}$ substrate. Compared with the $\mathrm{Au}-\mathrm{Ag}-\mathrm{Si}$ solder, Au-19.25Ag-12.80Ge solder has excellent wetting and spreading properties, and the wetting on $\mathrm{Ni}$ substrate is dominated by the reactive wetting mechanism, and the wetting ring is also produced. Due to the coupling enhancement of adding $\mathrm{Si}$ and $\mathrm{Ge}, \mathrm{Au}-20.1 \mathrm{Ag}-2.5 \mathrm{Si}-2.5 \mathrm{Ge}$ quaternary solder performed better than $\mathrm{Au}-\mathrm{Ag}-\mathrm{Si}$ solder and $\mathrm{Au}-\mathrm{Ag}-\mathrm{Ge}$ solders in the wettability test, giving higher spreading properties.

3.2. Au-In Solder. The In content of Au-In mediumtemperature solder is usually between $18 \%$ and $27 \%$ (mass fraction). The microstructure of Au-In solder consists of two intermetallic compounds: a cubic structure of $\mathrm{Au}_{7} \mathrm{In}_{3}$ ( $\gamma^{\prime}$ phase) and a three-oblique structure of AuIn ( $\beta$ phase) [71]. The airtightness and shear strength of the joint can meet the technical requirements of electronic device packaging, and thus the solder has a promotion and application prospect in the field of high-temperature packaging of microelectronic devices [72]. Figure 14 shows the interfacial microstructure of Au-In solder on the $\mathrm{Cu}$ substrate [73]. $\mathrm{Cu}$ dissolved into the molten solder matrix and reacted with In and Au elements during the wetting process. A thick interfacial layer, which was identified to be $\mathrm{Cu}-20 \mathrm{In}-14 \mathrm{Au}$ IMC, formed at the interface. But the $\mathrm{Au}$ content of $\mathrm{Au}$-In solder alloy should not exceed a certain extent; otherwise the reliability of solder joint would be greatly decreased due to its brittleness. It has been found that the joint resistivity of Au-In solder with high $\mathrm{Au}$ content was significantly increased during thermal cycling owing to the formation of defects [74]. The liquidus temperature of Au-In solder alloys is from 450 to $500^{\circ} \mathrm{C}$, and the spacing between the solidus and liquidus state is narrow, which means that the $\mathrm{Au}$-In alloy is a suitable medium-temperature solder alloy. Besides, the solder has excellent wettability and gap filling properties for various base metals such as gold-plated Kovar, oxygen-free copper, pure nickel, and pure silver. A uniform and dense weld structure can be obtained by soldering gold-plated Kovar alloy and pure nickel base material.

3.3. Au-Ga Solder. The Au-Ga-In solder alloy has a melting point between $282^{\circ} \mathrm{C}$ and $462^{\circ} \mathrm{C}$, which is in the melting temperature range of the gold-based medium- and lowtemperature solder alloys. By adjusting the composition of 

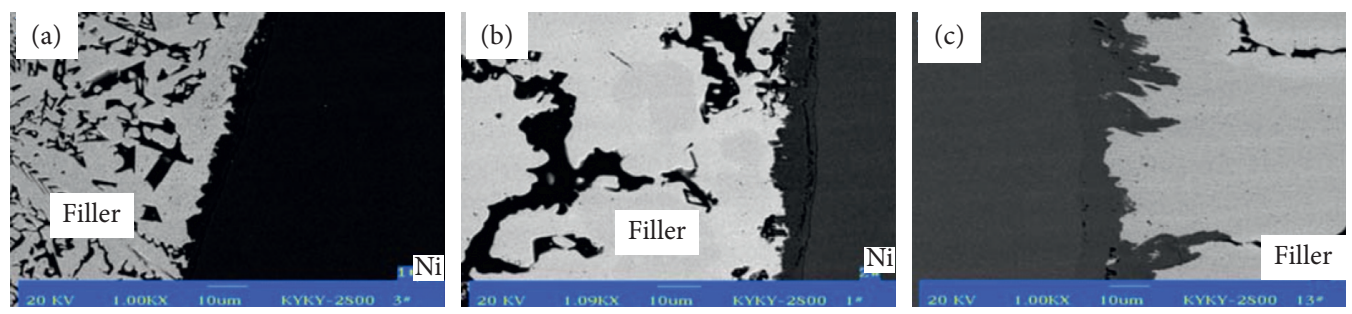

Figure 12: Cross-sectional electron images of Au-Ag-Si/Ni solder joint at different soldering temperatures: (a) $472^{\circ} \mathrm{C}$, (b) $492^{\circ} \mathrm{C}$, and (c) $512^{\circ} \mathrm{C}[66]$.

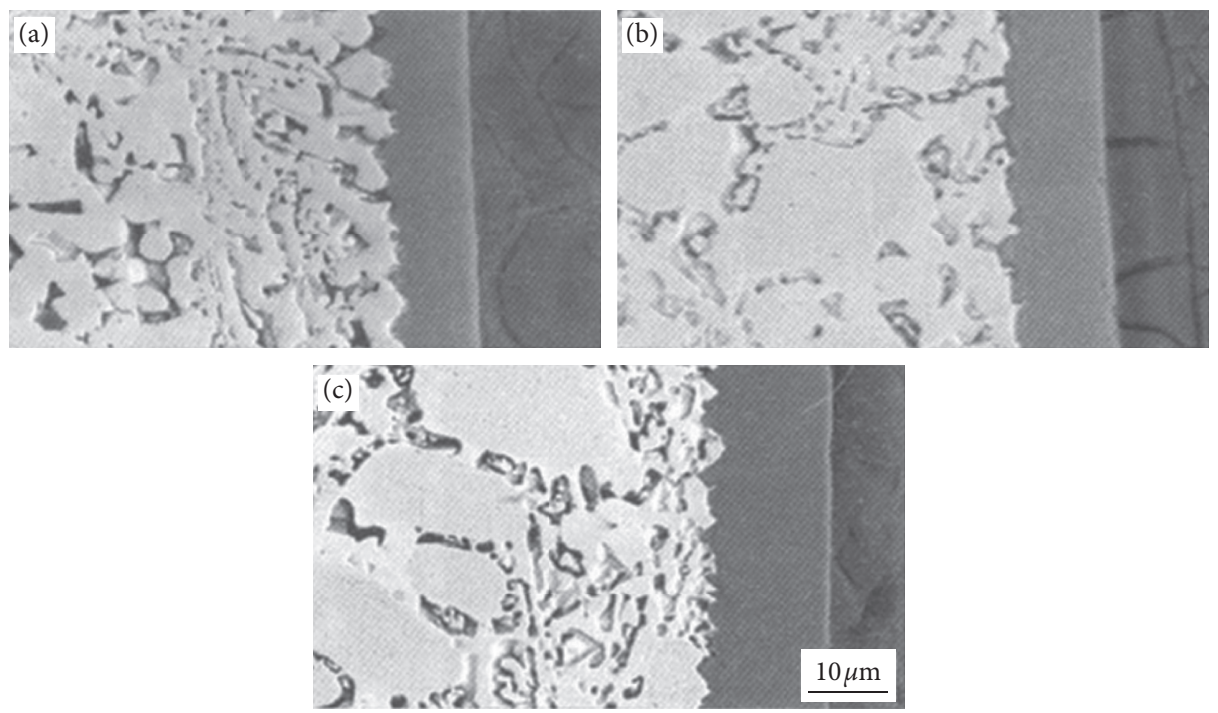

Figure 13: Cross-sectional electron images of $\mathrm{Au}-\mathrm{Ag}-\mathrm{Si} / \mathrm{Ni}$ solder joint at different soldering temperatures: (a) $510^{\circ} \mathrm{C}$, (b) $530^{\circ} \mathrm{C}$, and (c) $550^{\circ} \mathrm{C}[69]$.

TABLE 4: Au-Ag-based medium-temperature solders [70].

\begin{tabular}{|c|c|c|c|c|c|c|c|}
\hline \multirow{2}{*}{ Alloy } & \multicolumn{4}{|c|}{ Composition (at.\%) } & \multirow{2}{*}{ Solidus $\left({ }^{\circ} \mathrm{C}\right)$} & \multirow{2}{*}{ Liquidus $\left({ }^{\circ} \mathrm{C}\right)$} & \multirow{2}{*}{$\Delta \mathrm{T}\left({ }^{\circ} \mathrm{C}\right)$} \\
\hline & $\mathrm{Au}$ & $\mathrm{Ag}$ & $\mathrm{Si}$ & $\mathrm{Ge}$ & & & \\
\hline \multirow{6}{*}{$\mathrm{Au}-\mathrm{Ag}-\mathrm{Si}$} & 86.72 & 10.02 & 3.26 & - & 409 & 450 & 41 \\
\hline & 86.63 & 10.12 & 3.25 & - & 411 & 451 & 40 \\
\hline & 82.70 & 14.02 & 3.28 & - & 421 & 457 & 36 \\
\hline & 78.25 & 18.47 & 3.27 & - & 448 & 499 & 51 \\
\hline & 78.30 & 18.50 & 3.20 & - & 449 & 478 & 29 \\
\hline & 78.22 & 18.55 & 3.13 & - & 448 & 481 & 33 \\
\hline \multirow{4}{*}{$\mathrm{Au}-\mathrm{Ag}-\mathrm{Ge}$} & 58.5 & 19.5 & - & 22.0 & 410 & 449.8 & 39.8 \\
\hline & 60.0 & 15.0 & - & 25.0 & 401.1 & 441 & 39.9 \\
\hline & 67.95 & 19.25 & - & 12.80 & 446.76 & 494.4 & 47.64 \\
\hline & 77.32 & 12.62 & - & 10.06 & 405 & 431 & 26 \\
\hline$\overline{\mathrm{Au}-\mathrm{Ag}-\mathrm{Si}-\mathrm{Ge}}$ & 74.9 & 20.1 & 2.5 & 2.5 & 451.36 & 506.49 & 55.13 \\
\hline
\end{tabular}

the Au-Ga-In alloy, the gold-based medium-temperature solder and the gold-based low-temperature solder alloys with different melting temperatures can be obtained. The patent [22] proposed an Au-Ga-In ternary alloy. By adjusting the addition amounts of $\mathrm{Ga}$ and In elements in the alloy, a series of solder alloys with different melting points can be obtained, as shown in Table 5, and can meet the requirements of different products for the melting temperature of the solder.

\section{Preparation Methods of Au-Based Solder Alloys}

Although Au-based medium-low temperature solder alloys have excellent performance, their high brittleness makes them difficult to be processed by conventional manufacturing methods, which seriously restricts the application of these solders. In particular, the Au-Sn eutectic solder is most widely 


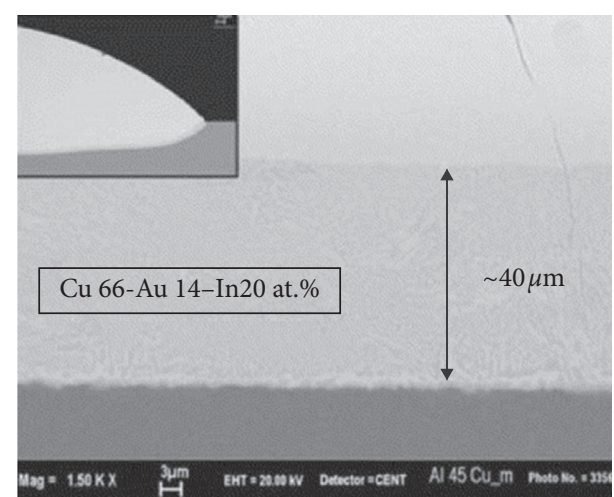

FIgURE 14: SEM micrographs of the cross section of the Au-In solder alloy on a pure $\mathrm{Cu}$ substrate [73].

used in electronic packaging and has the highest processing difficulty. In this regard, the researchers studied a number of special processing techniques to solve the manufacturing problem. At present, there are a few novel processing technologies, such as melt-casting and toughening process, laminated cold rolling process, electroplating deposition process, mechanical alloying process, and rapid solidification process.

4.1. Melt-Casting and Toughening Process. The melt-casting and toughening process is based on the traditional metalcasting process and introduces a hot calendaring process to refine the dendritic primary phase and the coarsening eutectic structure. Through the toughening annealing process, the alloy undergoes dynamic recrystallization to form evenly distributed small tissue. The fine structure improves the toughness of the alloy and thereby enhances the processing properties. The welding piece, foil material, and wire material are then prepared by mechanical blanking.

The melt-casting and toughening method can effectively promote the uniform alloying of the solder, improve the toughness of the solder through toughening annealing process, and provide favorable conditions for the subsequent mechanical blanking and other processes. However, the whole process uses multiple thermal processing and the operation process is cumbersome, which easily leads to the formation of some defects such as surface oxidation and introduction of impurities, affecting the performance of the solder joint.

4.2. Laminated Cold Rolling Process. The laminated cold rolling process, which is initially used for the processing of $\mathrm{Au}-\mathrm{Sn}$ eutectic solder alloys, can be divided into lamination composite process and lamination diffusion process. Due to the good ductility of gold and tin, gold strip and tin strip are layered together (at least 5 layers), precompressed into a composite billet by a lamination process, and then coldrolled into a foil of a desired specification, as shown in Figure 15. The lamination diffusion process is performed by homogenizing annealing treatment on the basis of the lamination composite process to realize alloying of $\mathrm{Au}-20 \mathrm{Sn}$ solder.
The Au-Sn eutectic solder prepared by the lamination cold rolling process is not easily oxidized and is easy to form, but the Au tape and the Sn tape are easily deformed during the rolling process, resulting in uneven solder component and insufficient alloying of the solder. In the soldering process, it is easy to cause segregation of chemical components, which results in an increasing melting temperature and affects the wettability of the solder, resulting in the weak formability of the solder alloy. Moreover, the uniform annealing temperature range of the composite strip after cold rolling is not easy to select. If the annealing temperature is too high, the Sn band will be melted. If the annealing temperature is too low, the atomic diffusion rate of the $\mathrm{Au} /$ Sn interface is slow, the production efficiency is low, and the solder cannot be prepared well.

4.3. Electroplating Deposition Process. The electroplating deposition process is mainly used for the preparation of $\mathrm{Au}-$ Sn eutectic solder. The method is to redox the ions containing $\mathrm{Au}$ and $\mathrm{Sn}$ to form elemental $\mathrm{Au}$ and elemental $\mathrm{Sn}$ and then deposit on the substrate. The operation process is as follows: First, a mask model of a certain shape is prepared on the substrate, and then the Au-Sn alloy plating solution is plated on the exposed surface of the substrate to form an $\mathrm{Au} /$ Sn film. After the plating is completed, the Au-Sn alloy foil is peeled off from the substrate. Using this process, Au-Sn bumps can be prepared on a flip chip by continuous plating [33], or Au-20Sn eutectic alloy plating can be prepared by codeposition, and the prepared solder plating layer has good bonding performance and good solderability on the $\mathrm{Cu}$ and Ni substrate.

The electroplating deposition process can precisely control the proportion of $\mathrm{Au}$ and $\mathrm{Sn}$ components, and various shapes of $\mathrm{Au}-20 \mathrm{Sn}$ solder layers can be prepared according to actual needs. The solder foil prepared by this method has the thinnest thickness, and a plurality of solder bumps on the same substrate can be completed by one plating, which greatly improves the efficiency and reduces the cost. However, this method is complicated in process and lacks flexibility, resulting in high electroplating technology and high maintenance cost, which limits its application. In addition, the need of a nontoxic and environmentally friendly alloy plating solution with good stability and long service life for plating is also an urgent problem to be solved $[75,76]$.

4.4. Mechanical Alloying Process. In the mechanical alloying process, Au powder and Sn powder are mixed in a mass ratio of $4: 1$ and then put them into a high-energy ball mill to achieve full alloying by ball milling. With the increase of ball milling time, the elemental $\mathrm{Au}$ decreases gradually, the proportion of IMCs increases, and the alloying degree of $\mathrm{Au}$ $20 \mathrm{Sn}$ increases. The alloy structure gradually changes from $\left(\xi-\mathrm{AuSn}_{2}+\delta\right.$-AuSn) phase to $\left(\xi-\mathrm{Au}_{5} \mathrm{Sn}+\delta\right.$-AuSn $)$ phase, and the hardness of the alloy increases. During the ball milling process, the Au-Sn powder is repeatedly deformed, broken, and welded by the intense collision of the ball, which causes the Au powder and the Sn powder to overcome the 
TAble 5: Au-Ga-In solders [22].

\begin{tabular}{|c|c|c|c|c|c|c|c|c|c|}
\hline \multirow{2}{*}{ No. } & \multicolumn{4}{|c|}{ Composition (at.\%) } & \multirow{2}{*}{ Hardness (HV) } & \multirow{2}{*}{ Processability } & \multirow{2}{*}{ Solidus $\left({ }^{\circ} \mathrm{C}\right)$} & \multirow{2}{*}{ Liquidus $\left({ }^{\circ} \mathrm{C}\right)$} & \multirow{2}{*}{$\Delta \mathrm{T}\left({ }^{\circ} \mathrm{C}\right)$} \\
\hline & $\mathrm{Au}$ & $\mathrm{Ga}$ & In & Sn & & & & & \\
\hline 1 & 84 & 13 & 3 & - & 242 & Good & 304 & 317 & 13 \\
\hline 2 & 82 & 10 & 8 & - & 267 & Good & 306 & 322 & 16 \\
\hline 3 & 83 & 10 & 7 & - & 290 & Good & 306 & 321 & 15 \\
\hline 4 & 81 & 10 & 9 & - & 292 & Good & 306 & 323 & 17 \\
\hline 5 & 82 & 11 & 7 & - & 300 & Good & 306 & 324 & 18 \\
\hline 6 & 83 & 9 & 8 & - & 301 & Good & 306 & 323 & 17 \\
\hline 7 & 81.95 & 10 & 8 & 0.05 & 292 & Good & 306 & 320 & 14 \\
\hline 8 & 81.19 & 9.9 & 7.92 & 0.99 & 300 & Good & 282 & 302 & 20 \\
\hline 9 & 67 & 25 & 8 & - & 180 & Good & 390 & 462 & 72 \\
\hline 10 & 65 & 18 & 17 & - & 224 & Good & 380 & 418 & 38 \\
\hline 11 & 62 & 13 & 25 & - & 257 & Good & 383 & 408 & 25 \\
\hline 12 & 84.8 & 15.2 & 0 & - & 210 & Good & 339 & 358 & 19 \\
\hline
\end{tabular}

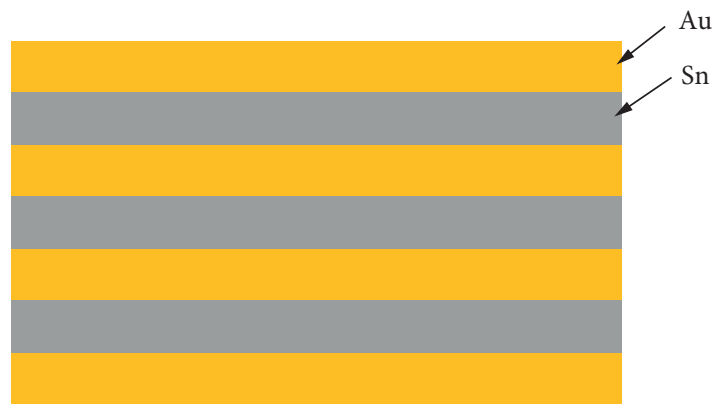

FIgURE 15: Gold-tin laminated soldering diagram.

reaction barrier and interdiffuse. Thereby, the mechanically alloyed Au-20Sn powder could be obtained.

The Au-20Sn powder prepared by mechanical alloying may be further processed by adding an additive to prepare $\mathrm{Au}-20 \mathrm{Sn}$ solder paste or by pressing and low-temperature sintering process to prepare solder piece in a specific shape. The Au-Sn powder prepared by high-energy ball milling does not achieve complete alloying, and at the same time, due to the large plastic deformation caused by ball milling, the dislocation density of the alloy powder increases, resulting in work hardening.

4.5. Rapid Solidification Process. The rapid solidification process is to spray the molten alloy from the nozzle, form a strip under the action of a roller having a high thermal conductivity (usually a copper roller), and control the foil thickness by controlling the surface speed of the roller. Under appropriate conditions, the foil strip is heat treated and finally formed. The rapid solidification method could be further divided into the single roll method and the double roll method, and the single roll method has a faster cooling rate and a wider application. Since rapid solidification can refine grains, reduce tissue segregation, and expand the solid solution limit of alloying elements, the strip solder prepared by this method generally has uniform composition and excellent soldering performance.
This method is costly but effective for the Au-based solder alloy, especially for these with high Au content, such as $\mathrm{Au}-20 \mathrm{Sn}$ and $\mathrm{Au}-12 \mathrm{Ge}$ solder alloys. Due to high brittleness, these solder alloys are very difficult to be processed by the conventional method to prepare solder foils and hence could be achieved by the rapid solidification process. According to this method, gold-based medium- and lowtemperature solders such as Au-Sn and Au-Ag-Ge can be prepared into a thin strip having a thickness of $0.1 \mathrm{~mm}$ or less [77]. What is more, compared with other methods, the process technology of rapid solidification is simple and hence gives a lower fabrication cost. In the field of novel electrical packaging where Au-based solder alloys are applied, the property of solder alloys is more emphasized than the cost. It has been clarified that Au-20Sn solder foil prepared by the rapid solidification process possesses higher wettability and mechanical property than melt-casting process [77]. Therefore, the rapid solidification process shows great potential for the manufacture of Au-based solder alloys.

Although the rapid solidification process has many advantages mentioned above, there are still many disadvantages for this method, which limit its industrial application. To ensure the uniform microstructure of alloy film, it puts much emphasis on the reliability of equipment, where the accurate design of spray nozzle and spraying voltage of row solder alloy are necessary. Moreover, the velocity stability of roller is very important for the suitable thickness and chemical component of solder foil. To apply the rapid solidification process in the industry, these relevant technology parameters and methods should be obtained and hence more investigations are necessary to meet the increasing requirement of electrical packaging.

\section{Investigation Prospect of Au-Based Solder Alloys}

Although with high price, Au-based solder alloys possess great thermal/electrical conductivity, wettability, oxidation resistance, and reliability, which make them the excellent electronic packaging materials for the novel electrical 
devices. At present, there are still some shortcomings for gold-based medium-low temperature solder alloys to limit their application and development, the majority of which are difficult processing of solder foils, easy segregation of chemical components, and high cost of use. The development of electrical industry and aerospace industry put higher property requirement of Au-based solder alloys. In this regard, the development trend of gold-based mediumand low-temperature solders mainly has the following aspects:

(1) Explore new preparation processes: Although the present preparing technologies have a positive effect on the manufacture of gold-based brittle solder alloys, the application and promotion of some fabrication technologies are limited due to low efficiency, high cost, and complicated operation. Many factors could affect the performance of the prepared solder alloy, and further investigations to enhance them are needed. Therefore, it is necessary to further optimize the present processing technologies and actively explore new preparation methods, reduce production costs, improve production efficiency, and avoid segregation and oxidation of solder components.

(2) Find methods to enhance the performance of present Au-based solder alloys: Adding new components is claimed to be able to improve the microstructure and performance of the solder alloys, giving a lower brittleness and cost. And the risk of chemical segregation could be reduced as well. The alloy elements and the particulate reinforcing phase can be added to the existing gold-based solder alloys as the new component either individually or in combination.

(3) Develop new alloy systems: On the one hand, in view of the shortcomings caused by the high gold content in the present Au-based low-temperature solder, it is of great significance to design alloy composition from a diversified perspective to reduce the $\mathrm{Au}$ content. At the same time of reducing the cost, the solder should have good solderability and formability. Only in this situation, the new solder alloy could be considered to replace the present Au-based low-temperature solder alloys. On the other hand, to meet the increasing requirements of packaging materials due to the trend of high integration and high power of electronic devices, a gold-based medium-temperature solder alloy system with a high thermal conductivity, low expansion coefficient, and a melting temperature of $400-600^{\circ} \mathrm{C}$ should be actively developed.

(4) New soldering process: Because gold-based solders are commonly used in high-end packaging, their packaging environment and requirements are generally demanding, so it is necessary to develop new soldering processes to achieve reliable packaging in nonvacuum and flux-free environments. In addition, the present soldering processes cannot meet the research and application of new Au-based medium- temperature solder alloys. The development of new soldering processes is an indispensable part of the promotion and application of Au-based mediumtemperature solders.

\section{Conclusion}

With the rapid development of the electronics industry, lead-free, miniaturized, and high-powered electronic products have placed higher demands on solder alloys. Au$\mathrm{Sn}, \mathrm{Au}-\mathrm{Si}, \mathrm{Au}-\mathrm{Ge}$, and other gold-based low-temperature solders will have wider application fields due to their excellent comprehensive properties. At the same time, the demand for gold-based medium-temperature solders will gradually increase. Low cost, easy preparation, high performance, etc. will become the main features of Au-based medium- and low-temperature solders. Therefore, reducing the gold content in the solder, solving the processing problems, and developing new gold-based alloy systems will become the investigation focus of Au-based solders in the future.

\section{Conflicts of Interest}

The authors declare that there are no conflicts of interest regarding the publication of this article.

\section{Acknowledgments}

This work was financially supported by the 2018 Jiangsu Province Post-Doctor Fund.

\section{References}

[1] S. He, R. Gao, Y.-A. Shen, J. Li, and H. Nishikawa, "Wettability, interfacial reactions, and impact strength of Sn-3.0Ag$0.5 \mathrm{Cu}$ solder/ENIG substrate used for fluxless soldering under formic acid atmosphere," Journal of Materials Science, vol. 55, no. 7, pp. 3107-3117, 2020.

[2] Y.-A. Shen, S. Zhou, J. Li et al., "Sn-3.0Ag-0.5Cu/Sn-58Bi composite solder joint assembled using a low-temperature reflow process for PoP technology," Materials \& Design, vol. 183, Article ID 108144, 2019.

[3] F. Wang, H. Chen, Y. Huang, L. Liu, and Z. Zhang, "Recent progress on the development of $\mathrm{Sn}$-Bi based low-temperature $\mathrm{Pb}$-free solders," Journal of Materials Science: Materials in Electronics, vol. 30, no. 4, pp. 3222-3243, 2019.

[4] R. M. Shalaby, M. Kamal, E. A. M. Ali, and M. S. Gumaan, "Design and properties of new lead-free solder joints using Sn-3.5Ag-Cu solder," Silicon, vol. 10, no. 5, pp. 1861-1871, 2018.

[5] R. Mostafa Shalaby, M. Kamal, E. A. M. Ali, and M. S. Gumaan, "Microstructural and mechanical characterization of melt spun process $\mathrm{Sn}-3.5 \mathrm{Ag}$ and $\mathrm{Sn}-3.5 \mathrm{Ag}-\mathrm{xCu}$ lead-free solders for low cost electronic assembly," Materials Science and Engineering: A, vol. 690, pp. 446-452, 2017.

[6] M. S. Gumaan, R. M. Shalaby, E. A. M. Ali, and M. Kamal, "Copper effects in mechanical, thermal and electrical properties of rapidly solidified eutectic Sn-Ag alloy," Journal of Materials Science: Materials in Electronics, vol. 29, no. 11, pp. 8886-8894, 2018. 
[7] J. Wang, S. Xue, P. Zhang, P. Zhai, and Y. Tao, "The reliability of lead-free solder joint subjected to special environment: a review," Journal of Materials Science: Materials in Electronics, vol. 30, no. 10, pp. 9065-9086, 2019.

[8] J. Wang, S. Xue, P. Zhang, Z. Wang, and P. Zhai, "Effect of extreme thermal shocking on the reliability of Sn50Pb49Sb1/ $\mathrm{Cu}$ solder joint," Journal of Materials Science: Materials in Electronics, vol. 31, no. 2, pp. 1421-1429, 2020.

[9] J. Sasaki, M. Itoh, T. Tamanuki et al., "Multiple-chip precise self-aligned assembly for hybrid integrated optical modules using Au-Sn solder bumps," IEEE Transactions on Advanced Packaging, vol. 24, no. 2, pp. 569-575, 2001.

[10] H. K. Kim, H. K. Liou, and K. N. Tu, "Three-dimensional morphology of a very rough interface formed in the soldering reaction between eutectic $\mathrm{SnPb}$ and $\mathrm{Cu}$," Applied Physics Letters, vol. 66, no. 18, pp. 2337-2339, 1995.

[11] H. K. Kim and K. N. Tu, "Kinetic analysis of the soldering reaction between eutectic $\mathrm{SnPb}$ alloy and $\mathrm{Cu}$ accompanied by ripening," Physical Review B, vol. 53, no. 23, pp. 16027-16034, 1996.

[12] K. N. Tu and K. Zeng, "Tin-lead ( $\mathrm{SnPb}$ ) solder reaction in flip chip technology," Materials Science and Engineering: R: Reports, vol. 34, no. 1, pp. 1-58, 2001.

[13] H. Liu, S. Xue, Y. Tao, W. Long, and S. Zhong, "Design and solderability characterization of novel $\mathrm{Au}-30 \mathrm{Ga}$ solder for high-temperature packaging," Journal of Materials Science: Materials in Electronics, vol. 31, no. 3, pp. 2514-2522, 2020.

[14] J. Kim, D. Kim, and C. C. Lee, "Fluxless flip-chip solder joint fabrication using electroplated Sn-rich Sn-Au structures," IEEE Transactions on Advanced Packaging, vol. 29, no. 3, pp. 473-482, 2006.

[15] L. Wang, S. Xue, H. Liu, and J. Wang, "Effect of oxygen content on reliability of Au-20Sn solder joints for the chiplevel package," Journal of Materials Science: Materials in Electronics, vol. 31, no. 2, pp. 1411-1420, 2020.

[16] H. Xu, Y. Shen, Y. Hu, J. Li, and J. Xu, "Fabrication of highly reliable joint based on $\mathrm{Cu} / \mathrm{Ni} / \mathrm{Sn}$ double-layer powder for high temperature application," Journal of Microelectronics and Electronic Packaging, vol. 16, no. 4, pp. 188-195, 2019.

[17] A. Larsson, T. A. Tollefsen, and K. E. Aasmundtveit, "Shear strength of off-eutectic Au Ge joints at high-temperature," Microelectronics Reliability, vol. 99, pp. 31-43, 2019.

[18] S. Hassam, J. Rogez, and Z. Bahari, "Experimental phase diagram of the AuSb-InSb section in the Au-In-Sb system," The Journal of Chemical Thermodynamics, vol. 70, pp. 168175, 2014.

[19] J.-W. Yoon, H.-S. Chun, and S.-B. Jung, "Liquid-state and solid-state interfacial reactions of fluxless-bonded Au-20Sn/ ENIG solder joint," Journal of Alloys and Compounds, vol. 469, no. 1-2, pp. 108-115, 2009.

[20] J. Wang, Y. J. Liu, L. B. Liu, H. Y. Zhou, and Z. P. Jin, "Thermodynamic modeling of the Au-Sb-Si ternary system," Journal of Alloys and Compounds, vol. 509, no. 6, pp. 30573064, 2011.

[21] C. Datian, W. Zhifa, W. Huabo, and L. Jinwen, "Preparation and property of novel-type $\mathrm{Au}-19.25 \mathrm{Ag}-12.80 \mathrm{Ge}$ solder alloy," Rare Metal Materials and Engineering, vol. 37, no. 4, pp. 690-693, 2008.

[22] J. Wang, H.-s. Liu, L.-b. Liu, and Z.-p. Jin, “Thermodynamic description of Au-Ag-Si ternary system," Transactions of Nonferrous Metals Society of China, vol. 17, no. 6, pp. 1405$1411,2007$.

[23] M. O. Alam, Y. C. Chan, and K. N. Tu, "Elimination of Auembrittlement in solder joints on $\mathrm{Au} / \mathrm{Ni}$ metallization,"
Journal of Materials Research, vol. 19, no. 5, pp. 1303-1306, 2004.

[24] J. Wang, Y. J. Liu, C. Y. Tang, L. B. Liu, H. Y. Zhou, and Z. P. Jin, "Thermodynamic description of the Au-Ag-Ge ternary system," Thermochimica Acta, vol. 512, no. 1-2, pp. 240-246, 2011.

[25] O. E. Awe and O. M. Oshakuade, "Theoretical prediction of thermodynamic activities of liquid Au-Sn-X $(\mathrm{X}=\mathrm{Bi}, \mathrm{Sb}, \mathrm{Zn})$ solder systems," Physica B: Condensed Matter, vol. 507, pp. 84-94, 2017.

[26] V. Chidambaram, J. Hattel, and J. Hald, "High-temperature lead-free solder alternatives," Microelectronic Engineering, vol. 88, no. 6, pp. 981-989, 2011.

[27] D. G. Ivey, "Microstructural characterization of Au/Sn solder for packaging in optoelectronic applications," Micron, vol. 29, no. 4, pp. 281-287, 1998.

[28] J. W. Elmer and R. P. Mulay, "Superplastic creep of AuSn eutectic solder alloy," Scripta Materialia, vol. 120, pp. 14-18, 2016.

[29] S. Kim, K.-S. Kim, K. Suganuma, and G. Izuta, "Interfacial reactions of Si die attachment with $\mathrm{Zn}-\mathrm{Sn}$ and Au-20Sn high temperature lead-free solders on $\mathrm{Cu}$ substrates," Journal of Electronic Materials, vol. 38, no. 6, pp. 873-883, 2009.

[30] H.-m. Chung, C.-m. Chen, C.-p. Lin, and C.-j. Chen, "Microstructural evolution of the $\mathrm{Au}-20 \mathrm{wt}$ \% $\mathrm{Sn}$ solder on the $\mathrm{Cu}$ substrate during reflow," Journal of Alloys and Compounds, vol. 485, pp. 219-224, 2009.

[31] J. Peng, H. S. Liu, H. B. Ma, X. M. Shi, and R. C. Wang, "Microstructure evolution and mechanical reliability of $\mathrm{Cu} /$ $\mathrm{Au}-\mathrm{Sn} / \mathrm{Cu}$ joints during transient liquid phase bonding," Journal of Materials Science, vol. 53, no. 12, pp. 9287-9296, 2018.

[32] H. G. Song, J. W. Morris, and M. T. McCormack, "The microstructure of ultrafine eutectic Au-Sn solder joints on $\mathrm{Cu}$," Journal of Electronic Materials, vol. 29, no. 8, pp. 1038-1046, 2000.

[33] J.-W. Yoon, H.-S. Chun, and S.-B. Jung, "Reliability evaluation of Au-20Sn flip chip solder bump fabricated by sequential electroplating method with $\mathrm{Sn}$ and $\mathrm{Au}, "$ Materials Science and Engineering: A, vol. 473, no. 1-2, pp. 119-125, 2008.

[34] J.-H. Park, J.-H. Lee, Y.-H. Lee, and Y.-S. Kim, "Reaction characteristics of the Au-Sn solder with under-bump metallurgy layers in optoelectronic packages," Journal of Electronic Materials, vol. 31, no. 11, pp. 1175-1180, 2002.

[35] J.-W. Yoon, B.-I. Noh, and S.-B. Jung, "Interfacial reaction between Au-Sn solder and Au/Ni-metallized Kovar," Journal of Materials Science: Materials in Electronics, vol. 22, no. 1, pp. 84-90, 2011.

[36] L. Wang, S. Xue, and H. Liu, "Effect of oxygen content on wettability, microstructure and solderability of Au-20Sn solders," Journal of Materials Science: Materials in Electronics, vol. 29, no. 24, pp. 21130-21137, 2018.

[37] J. W. Ronnie Teo, F. L. Ng, L. S. Kip Goi et al., "Microstructure of eutectic $80 \mathrm{Au} / 20 \mathrm{Sn}$ solder joint in laser diode package," Microelectronic Engineering, vol. 85, no. 3, pp. 512-517, 2008.

[38] J. Wang, S. Xue, Z. Lv, L. Wang, H. Liu, and L. Wen, "Effect of gamma-ray irradiation on microstructure and mechanical property of Sn63Pb37 solder joints," Journal of Materials Science: Materials in Electronics, vol. 29, no. 24, pp. 2072620733, 2018.

[39] J. Wang, S. Xue, J. Wang, P. Zhang, Y. Tao, and Z. Wang, "Comparative study on the reliability of $\mathrm{SnPbSb}$ solder joint under common thermal cycling and extreme thermal 
shocking," Journal of Materials Science: Materials in Electronics, vol. 31, no. 7, pp. 5731-5737, 2020.

[40] V. Chidambaram, J. Hattel, and J. Hald, "Design of lead-free candidate alloys for high-temperature soldering based on the Au-Sn system," Materials \& Design, vol. 31, no. 10, pp. 4638-4645, 2010.

[41] J.-W. Yoon, H.-S. Chun, B.-I. Noh et al., "Mechanical reliability of Sn-rich Au-Sn/Ni flip chip solder joints fabricated by sequential electroplating method," Microelectronics Reliability, vol. 48, no. 11-12, pp. 1857-1863, 2008.

[42] A. Katz, K. W. Wang, F. A. Baiocchi et al., "Ti/Pt/Au-Sn metallization scheme for bonding of InP-based laser diodes to chemical vapor deposited diamond submounts," Materials Chemistry and Physics, vol. 33, no. 3-4, pp. 281-288, 1993.

[43] C. H. Lee, K. L. Tai, D. D. Bacon et al., "Bonding of InP laser diodes by $\mathrm{Au}-\mathrm{Sn}$ solder and tungsten-based barrier metallization schemes," Semiconductor Science and Technology, vol. 9, no. 4, pp. 379-386, 1994.

[44] Y. T. Lai and C. Y. Liu, "Study of wetting reaction between eutectic AuSn and Au foil," Journal of Electronic Materials, vol. 35, no. 1, pp. 28-34, 2006.

[45] J.-W. Yoon, H.-S. Chun, J.-M. Koo, and S.-B. Jung, “Au-Sn flip-chip solder bump for microelectronic and optoelectronic applications," Microsystem Technologies, vol. 13, no. 11-12, pp. 1463-1469, 2007.

[46] V. Chidambaram, J. Hald, and J. Hattel, "Development of AuGe based candidate alloys as an alternative to high-lead content solders," Journal of Alloys and Compounds, vol. 490, no. 1-2, pp. 170-179, 2010.

[47] V. Chidambaram, H. B. Yeung, and G. Shan, "Reliability of $\mathrm{Au}-\mathrm{Ge}$ and $\mathrm{Au}-\mathrm{Si}$ eutectic solder alloys for high-temperature electronics," Journal of Electronic Materials, vol. 41, no. 8, pp. 2107-2117, 2012.

[48] F. Lang, H. Yamaguchi, H. Ohashi, and H. Sato, "Improvement in joint reliability of $\mathrm{SiC}$ power devices by a diffusion barrier between $\mathrm{Au}-\mathrm{Ge}$ solder and $\mathrm{Cu} / \mathrm{Ni}(\mathrm{P})$-metalized ceramic substrates," Journal of Electronic Materials, vol. 40, no. 7, pp. 1563-1571, 2011.

[49] M. Shimaoka, K. Fukuda, and T. Kumazawa, "Bondingstructure design of lenses for LD modules," Electronics and Communications in Japan (Part II: Electronics), vol. 80, no. 5, pp. 17-23, 1997.

[50] N. Weyrich, S. Jin, L. I. Duarte, and C. Leinenbach, "Joining of $\mathrm{Cu}, \mathrm{Ni}$, and $\mathrm{Ti}$ using Au-Ge-based high-temperature solder alloys," Journal of Materials Engineering and Performance, vol. 23, no. 5, pp. 1585-1592, 2014.

[51] V. Chidambaram, H. B. Yeung, and G. Shan, "High reliability gold based solder alloys for micro-electronics packaging for high temperature applications," in Proceedings of 2012 19th IEEE International Symposium on the Physical and Failure Analysis of Integrated Circuits, p. 6, IEEE, Singapore, July 2012.

[52] F. Q. Lang, H. Yamaguchi, H. Nakagawa, and H. Sato, "SolidState interfacial reaction between eutectic Au-Ge solder and $\mathrm{Cu} / \mathrm{Ni}(\mathrm{P}) / \mathrm{Au}$ metalized ceramic substrate and its suppression," Journal of Materials Science \& Technology, vol. 31, no. 5, pp. 445-452, 2015.

[53] C. Leinenbach, F. Valenza, D. Giuranno, H. R. Elsener, S. Jin, and R. Novakovic, "Wetting and soldering behavior of eutectic $\mathrm{Au}-\mathrm{Ge}$ alloy on $\mathrm{Cu}$ and $\mathrm{Ni}$ substrates," Journal of Electronic Materials, vol. 40, no. 7, pp. 1533-1541, 2011.

[54] N. Eustathopoulos, M. G. Nicholas, and B. Drevet, Wettability at High Temperatures, Vol. 3, Elsevier, Oxford, UK, 1999.
[55] Z. Wang and P. Wynblatt, "Wetting and energetics of solid Au andAu-Ge/SiC interfaces," Acta Materialia, vol. 46, no. 14, pp. 4853-4859, 1998.

[56] A. Larsson, T. A. Tollefsen, O. M. Løvvik, and K. E. Aasmundtveit, "A review of eutectic Au-Ge solder joints," Metallurgical and Materials Transactions A, vol. 50, no. 10, pp. 4632-4641, 2019.

[57] T. J. Harpster and K. Najafi, "Field-assisted bonding of glass to $\mathrm{Si}-\mathrm{Au}$ eutectic solder for packaging applications," in Proceedings of the Sixteenth Annual International Conference on Micro Electro Mechanical Systems, pp. 630-633, IEEE, Kyoto, Japan, January 2003.

[58] N. P. Weyrich, Joining of Metals and Ceramics Using Au-(Ge, Si)-Based Solder Alloys, ETH Zurich, Zürich, Switzerland, 2015.

[59] A.-L. Tiensuu, M. Bexell, J.-Å. Schweitz, L. Smith, and S. Johnsson, "Assembling three-dimensional microstructures using gold-silicon eutectic bonding," Sensors and Actuators A: Physical, vol. 45, no. 3, pp. 227-236, 1994.

[60] E. Jing, B. Xiong, and Y. Wang, "The Au/Si bonding interface studied by infrared microscope," Materials Letters, vol. 64, no. 7, pp. 827-829, 2010.

[61] R. F. Wolffenbuttel, "Low-temperature intermediate Au-Si wafer bonding; eutectic or silicide bond," Sensors and Actuators A: Physical, vol. 62, no. 1-3, pp. 680-686, 1997.

[62] K. N. Tu and S. H. Libertini, "Wetting of quartz surfaces by Au-Si eutectic melt," Journal of Applied Physics, vol. 48, no. 1, pp. 420-421, 1977.

[63] Y. V. Naidich, V. Zhuravlev, and N. Krasovskaya, "The wettability of silicon carbide by Au-Si alloys," Materials Science and Engineering: A, vol. 245, no. 2, pp. 293-299, 1998.

[64] B. Ressel, K. C. Prince, S. Heun, and Y. Homma, "Wetting of Si surfaces by Au-Si liquid alloys," Journal of Applied Physics, vol. 93, no. 7, pp. 3886-3892, 2003.

[65] D. Cui, Z. Wang, J. Zhou, G. Jiang, and H. Wu, "Microstructure and properties of new type Au-20.1Ag-2.5Si-2.5Ge medium-temperature solder," The Chinese Journal of Nonferrous Metals, vol. 17, no. 9, pp. 1501-1505, 2007.

[66] W. Mo, Z. Wang, G. Jiang, and W. Haishan, "Study of a new type of Au-Ag-Si intermediate temperature eutectic solder," Rare Metal Materials and Engineering, vol. 34, no. 3, pp. 497-500, 2005.

[67] D. Cui, Z. Wang, G. Jiang, and J. Zhou, "Welding performance study on Au-19.25Ag-12.80Ge brazing alloy," Chinese Journal of Rare Metals, vol. 32, pp. 269-273, 2008.

[68] D. Cui, Z. Wang, Z. Hu, W. Liu, and L. Liu, "Microstructure and welding properties of single-roller melt spinned Au-19.25 Ag-12.80 Ge solder ribbon," Rare Metal Materials and Engineering, vol. 41, pp. 442-446, 2012.

[69] D. Cui, Z. Wang, J. Zhou, H. Wu, and J. Liu, "Properties and welding interface characterization of new-type Au-Ag-Ge brazing alloy," Journal of Center South University, vol. 38, no. 6, pp. 1050-1054, 2007.

[70] W. Mo, Z. Wang, H. Wang, and H. Yang, "A primary study of the Au-Ag-Si solder," Precious Metals, vol. 25, pp. 45-51, 2004.

[71] J. Lian, S. J. W. Chun, M. S. Goorsky, and J. Wang, "Mechanical behavior of Au-In intermetallics for low temperature solder diffusion bonding," Journal of Materials Science, vol. 44, no. 22, pp. 6155-6161, 2009.

[72] B. J. Grummel, Z. J. Shen, H. A. Mustain, and A. R. Hefner, "Thermo-mechanical characterization of Au-in transient liquid phase bonding die-attach," IEEE Transactions on 
Components, Packaging and Manufacturing Technology, vol. 3, no. 5, pp. 716-723, 2013.

[73] F. Gnecco, E. Ricci, S. Amore et al., "Wetting behaviour and reactivity of lead free $\mathrm{Au}-\mathrm{In}-\mathrm{Sn}$ and $\mathrm{Bi}$-In-Sn alloys on copper substrates," International Journal of Adhesion and Adhesives, vol. 27, no. 5, pp. 409-416, 2007.

[74] B. J. Grummel, H. A. Mustain, Z. J. Shen, J. C. Elmes, and A. R. Hefner, "Reliability characterization of Au-in transient liquid phase bonding through electrical resistivity measurement," IEEE Transactions on Components, Packaging and Manufacturing Technology, vol. 5, no. 12, pp. 1726-1733, 2015.

[75] J. Doesburg and D. G. Ivey, "Microstructure and preferred orientation of Au-Sn alloy plated deposits," Materials Science and Engineering: B, vol. 78, no. 1, pp. 44-52, 2000.

[76] T. N. Vorobyova and O. N. Vrublevskaya, "Electrochemical deposition of gold-tin alloy from ethylene glycol electrolyte," Surface and Coatings Technology, vol. 204, no. 8, pp. 13141318, 2010.

[77] S. Liu, D. Zhang, J. Xiong et al., "Microstructure evolution and properties of rapidly solidified Au-20Sn eutectic solder prepared by single-roll technology," Journal of Alloys and Compounds, vol. 781, pp. 873-882, 2019. 